\title{
The Possible use of Equivalent Homogeneous Subsoil Models for 1D Seismic Response Analyses in Seismic Microzonation Studies
}

\section{Stefania Fabozzi ( $\nabla$ stefania.fabozzi@igag.cnr.it)}

Istituto di geologia ambientale e geoingegneria Consiglio Nazionale delle Ricerche https://orcid.org/0000-0002-8024-7913

\section{Albarello Dario}

University of Siena: Universita degli Studi di Siena

\section{Pagliaroli Alessandro}

Gabriele d'Annunzio University of Chieti and Pescara: Universita degli Studi Gabriele d'Annunzio Chieti

\section{Pescara}

\section{Moscatelli Massimiliano}

Istituto di geologia ambientale e geoingegneria Consiglio Nazionale delle Ricerche

\section{Research Article}

Keywords: site response, nonlinear soil behavior, seismic microzonation. numerical simulations

Posted Date: August 10th, 2021

DOl: https://doi.org/10.21203/rs.3.rs-786233/v1

License: (c) (1) This work is licensed under a Creative Commons Attribution 4.0 International License. Read Full License

Version of Record: A version of this preprint was published at Bulletin of Earthquake Engineering on January 9th, 2022. See the published version at https://doi.org/10.1007/s10518-021-01273-z. 


\title{
1 The possible use of equivalent homogeneous subsoil models for 1D seismic response analyses in seismic microzonation studies
}

\author{
Fabozzi Stefania ${ }^{\mathrm{a}^{*}}$, Albarello Dario ${ }^{\mathrm{b}, \mathrm{a}}$, Pagliaroli Alessandro ${ }^{\mathrm{c}, \mathrm{a}}$, Moscatelli \\ Massimiliano $^{\mathrm{a}}$ \\ ${ }^{a}$ Institute of Environmental Geology and Geoengineering - National Research Council of Italy \\ ${ }^{\mathrm{b}}$ Department of Physics, Earth and Environmental Sciences - University of Siena \\ c Department of Engineering and Geology - University of Chieti Pescara G. D’Annunzio \\ *stefania.fabozzi@igag.cnr.it
}

Keywords: site response, nonlinear soil behavior, seismic microzonation. numerical simulations

\begin{abstract}
The possibility is here explored to use an 'equivalent' homogeneous configuration to simulate 1D seismic response of heterogeneous engineering-geological bodies when relatively weak seismic impedance contrasts $(\leq 150 \mathrm{~m} / \mathrm{s})$ only exist above the seismic bedrock. This equivalent configuration is obtained by considering an equivalent Vs value the harmonic average of the actual Vs values and a linear combination of $\mathrm{G} / \mathrm{G}_{0}$ and $\mathrm{D}$ curves relative to the lithotechnical components present in the actual configuration. To evaluate feasibility of this approach, a wide set of numerical simulations was carried out by randomly generating subsoil layering including sequences of alternating thin layers of geotechnical units (e.g., sands and clays) each characterized by a characteristic nonlinear curve. Outcomes of these simulations are compared with those provided by considering a single homogeneous layer characterized by equivalent nonlinear curves obtained as a weighted average of the original curves. By comparing the heterogeneous and the homogeneous columns seismic response in terms of amplification factors and fundamental period, the results confirm the possibility to model a $1 \mathrm{D}$ column characterized by a generic lithostratigraphic succession with an equivalent one without introducing significative errors that, at least for the studied cases, do not exceed the $6 \%$. This conclusion is substantially confirmed by extending the comparison to a real case, i.e. the $113 \mathrm{~m}$-thick heterogeneous soil profile at Mirandola site (Norther Italy), presented in the last part.
\end{abstract}

\section{INTRODUCTION}

Accounting for nonlinear behavior of soil under dynamic loads is necessary to provide a consistent modelling of local seismic response during strong earthquakes (Kramer, 1996). Two methods of analysis can essentially be chosen to this purpose: equivalent linear, based on a series of iterative analyses assuming a visco-elastic soil behavior, or a true nonlinear approach, this latter involving a broad range of simplified (i.e., hyperbolic family models) and advanced soil constitutive models (Hashash et al., 2010). The nonlinear curves, i.e. the normalized shear modulus $\left(\mathrm{G} / \mathrm{G}_{0}-\gamma\right)$ and the damping ratio (D- $\gamma$ ) curves, are directly employed in the equivalent linear strategy or used to calibrate the constitutive parameters in the true nonlinear approach. In the Seismic Microzonation (SM) studies the equivalent linear analysis is still the preferred approach because the limited data generally available on cyclic behavior as well as the large number of numerical simulations to be carried out (Pagliaroli, 2018).

A crucial step in these analyses is defining variation of shear modulus and damping ratio when excitation strength increases $\left(\mathrm{G} / \mathrm{G}_{0}-\gamma\right.$ and $\mathrm{D}-\gamma$ curves $)$. These can be obtained ad hoc from laboratory 
cyclic or dynamic tests (e.g., resonant column, cyclic simple shear, torsional shear tests). In general, these data are provided by testing relatively small homogenous specimens assumed to be representative of the geological body of interest. However, actual soil structure is characterized by significant lithological heterogeneities (e.g., lithotypes alternating with depth) at the scale of meters or less in the lack of sharp seismic impedance contrasts. This is typically the case of flyshoid formations characteristic of many recent tectonic belts, of wide sedimentary basins affected by glaciation cycles, coastal plains in the presence of ingression/regression cycles, etc.

A complete characterization of all the lithological units, is in most cases, cannot be afforded due to relatively high costs of this kind of analyses. Moreover, technical difficulties also prevent an extensive characterization of coarse grained soils (sands, gravels, pebbles, etc.). This last problem, also impose the use of modulus reduction and damping available in the technical literature and representative of data obtained worldwide where expensive studies were allowed to be performed.

The above problems are also enhanced when extensive seismic response studies are of concern and detailed geotechnical soil characterization cannot be easily performed. This is the case of site response analyses for SM, where subsoil investigations are carried out at urban scale and therefore a detailed characterization of stratigraphic profile as well as mechanical proprieties is not available in the numerical simulations. As an example, no more than two undisturbed samples for each municipality were available in the SM studies for the reconstruction after the Central Italy 2016 seismic sequence (Pergalani et al., 2020).

Another problem arising in these studies is the general lack of borehole data allowing a direct lithotechnical characterization of the soil structure. In most cases (in particular in the Italian practice), soil structure is inferred by geological considerations and indirect geophysical investigations (e.g., SM-WG, 2008; Albarello et al., 2015; Albarello, 2017; Moscatelli et al., 2020). This implies that soil characterization is performed in terms of engineering-geological categories, (TCSM, 2020, 2021; Amanti et al., 2020), by grouping the different rock-units into two main categories: "Cover terrains" and "Geological bedrock" units, on the base of their lithological feature and stratigraphic position. Within each of these wide groups, a number of subgroups (Engineering Geological Units, EGU in the following) is identified by considering macroscopic features and other geological considerations (e.g., Catalano et al., 2019; Amanti et al., 2020). These EGU, are inherently heterogenous in terms geotechnical behavior and this makes difficult their use in seismic response modelling.

For SM purposes, an attractive simplification is to replace the heterogeneous subsoil model with a homogeneous equivalent one characterized by a very close seismic response at surface (in terms of response spectra and amplification factors). This operation requires the definition of an equivalent shear wave velocity, $\mathrm{Vs}_{\text {,eq }}$, and equivalent variation curves of the shear modulus $\mathrm{G}_{\mathrm{eq}} / \mathrm{G}_{0}-\gamma$ and the damping ratio $\mathrm{D}_{\mathrm{eq}}-\gamma$.

In this paper, a methodology was proposed to test the possibility of define homogeneous columns equivalent to the heterogeneous ones actually representative of the EGU unit of concern. For the scope, an extensive parametric study, consisting in 1D frequency-domain equivalent linear site response analyses, was carried out.

Overall, in presence of lithostratigraphic alternations like the ones studied in this work (i.e., sand-silt and sand-gravel alternations) grossly characterized in terms of relative importance of each lithotype within the stratigraphic succession, the possibility to consider in computations an 'equivalent' homogeneous counterpart defined by only considering the percentage of the soil column represented by each lithotype, seems to be feasible, at least when relatively weak impedance contrasts only exist above the seismic bedrock.

In the first part of the paper, some preliminary analyses are presented aiming at testing a possible strategy to define equivalent curves representative of the nonlinear behavior of a heterogeneous body. In particular, some simple configurations are considered on purpose. In the second part, outcomes of an extensive analysis are presented by supporting effectiveness of the proposed approach finally tested with the real case of Mirandola site in north of Italy. 


\section{PRELIMINARY ANALYSIS}

Consider a $1 \mathrm{D}$ heterogeneous column where the upper layer is constituted by sand and the lower one by silt overlaying the bedrock. Both layers have the same thickness $\left(\mathrm{H}_{1}=\mathrm{H}_{2}=25 \mathrm{~m}\right)$, the same shear wave velocity $\left(\mathrm{Vs}_{1}=\mathrm{Vs}_{2}=350 \mathrm{~m} / \mathrm{s}\right)$, the same unit weight $\left(\gamma_{1}=\gamma_{2}=20 \mathrm{kN} / \mathrm{m}^{3}\right)$ while differ for the nonlinear response since different curves of the normalized shear modulus, $\mathrm{G} / \mathrm{G}_{0}$, and damping ratio, D, with shear strain, $\gamma$, were assigned: for sands we considered Seed and Idriss (1970) mean curve, for silts, Vucetic and Dobry (1991) curves relative to Plasticity Index (PI) 15-30-50. The bedrock in characterized by the same unit weight and Vs of the overlying layers in order to avoid the presence of seismic impedance contrasts at the bottom of the model.

In order to define a 1D equivalent column (i.e., model characterized by the same seismic response of the heterogeneous column) representative of the corresponding geological-technical unit as defined within the SM studies, it is necessary to calibrate equivalent variation curves $\left(\mathrm{G}_{\mathrm{eq}} / \mathrm{G}_{0}-\gamma\right.$ and $\left.\mathrm{D}_{\mathrm{eq}}-\gamma\right)$ able to provide, on average, the seismic response of the target column at surface. The input motion is a sinusoidal signal (frequency equal to $5 \mathrm{~Hz}$ and number of cycles equal to 10) with amplitude ranging from $0,001 \mathrm{~g}$ to $2 \mathrm{~g}$.

The procedure employed to set equivalent $\mathrm{Vs}$ and nonlinear curves are described in the following. The equivalent normalized shear modulus curve was calculated by means of the following equation

$\mathrm{G}_{\mathrm{eq}}=\frac{\gamma \mathrm{V}_{\mathrm{s}, \mathrm{eq}}^{2}}{\mathrm{~g}}$

where $\mathrm{Vs}_{\text {,eq }}$ is the ratio between the total column height $\mathrm{H}$ and the travel time, $\mathrm{dt}$, of the wave propagating from the bedrock up to the surface of the heterogeneous model. The relevant dt values are obtained by considering phase shift between input (time history at the bottom) and output (time history at the free surface) signals. Repeating this procedure for all considered wave amplitudes (from $0,001 \mathrm{~g}$ to $2 \mathrm{~g}$ ) allowing to explore the response at increasing shear strains, the corresponding values of $\mathrm{Vs}_{\mathrm{eq}}$ and $\mathrm{G}_{\mathrm{eq}}$ are shown in Table 1, for Vucetic and Dobry (1991) PI = 30 curves for the silt layer. For the construction of $\mathrm{G}_{\mathrm{eq}} / \mathrm{G}_{0}-\gamma$ curve, the shear strain levels corresponding to the different amplitudes of input motion were obtained as harmonic mean value of the maximum shear strain profiles from equation

$\gamma_{\max }=\frac{H}{\Sigma \frac{H_{i}}{\gamma_{\max , i}}}$

as shown in Figure 1a and finally multiplied for 0,65 to obtain the effective value. For the construction of $D_{\text {eq }}-\gamma$ curve, the following equation

$D_{\text {eq }}=\frac{2\left(\frac{I}{A\left(f_{1}\right)}\right)-2}{\pi I}$

was obtained by inverting the amplification function expression available for the case of homogeneous visco-elastic layer overlaying deformable substratum and was used to calculate the equivalent damping associated to the corresponding stain level. In Equation 3, $A\left(f_{1}\right)$ is the amplitude of the amplification function in correspondence of the first natural resonance frequency while $I$ is the contrast of impedance between the bedrock and the equivalent shear wave velocity. 

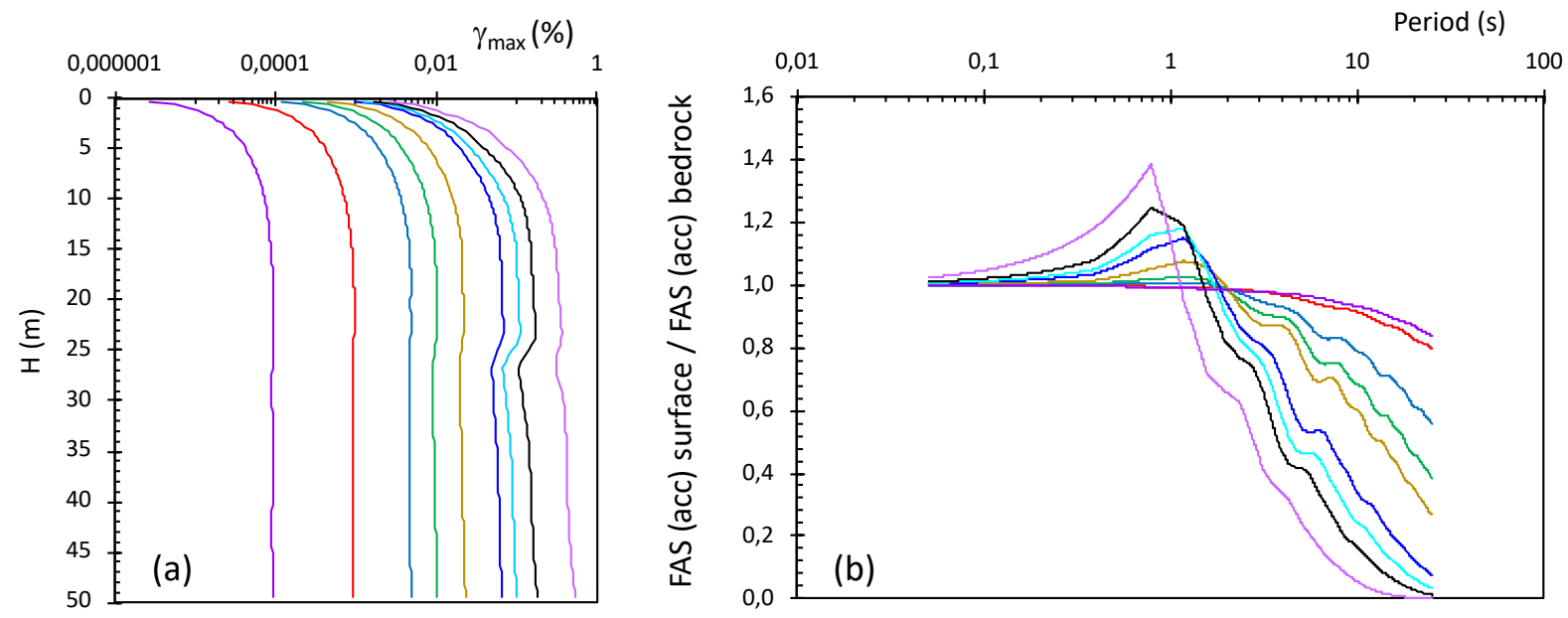

143

$-0,01 \mathrm{~g}-0,05 \mathrm{~g}-0,1 \mathrm{~g}-0,2 \mathrm{~g}-0,5 \mathrm{~g}-0,7 \mathrm{~g} \quad-1 \mathrm{~g} \quad-2 \mathrm{~g} \quad-0,001 \mathrm{~g}$

Figure 1. Outcomes of a $1 D$ linear equivalent numerical model for the heterogeneous column including sand and silt by considering different dynamic loads. As concerns nonlinear behavior of sands the mean curves provided by Seed and Idriss (1970) were considered. The curves provided by Vucetic and Dobry (1991) for PI = 30 have been adopted curves for silt. (a) maximum shear strain profiles and (b) amplification functions for signal amplitudes ranging from $0,001 \mathrm{~g}$ to $2 \mathrm{~g}$.

Note that impedance contrast $\mathrm{I}$ is higher than 1 in the nonlinear range due to the decay of shear modulus at increasing of shear strain.

In this way, equivalent decay curves $G_{e q} / G_{0}-\gamma$ and $D_{e q}-\gamma$ have been obtained (Figure 2). All parameters calculated to define $\mathrm{G}_{\mathrm{eq}} / \mathrm{G}_{0}-\gamma$ and $\mathrm{D}_{\mathrm{eq}}-\gamma$ are reported in Table 1 considering, as example, only Vucetic and Dobry (1991) PI = 30 curves for silt.

\begin{tabular}{c|ccccccccc}
\hline \multicolumn{1}{c}{ PGA wave } & $\mathbf{0 , 0 0 1 g}$ & $\mathbf{0 , 0 1 g}$ & $\mathbf{0 , 0 5 g}$ & $\mathbf{0 , 1 g}$ & $\mathbf{0 , 2 g}$ & $\mathbf{0 , 5 g}$ & $\mathbf{0 , 7 g}$ & $\mathbf{1 g}$ & $\mathbf{2 g}$ \\
\hline $\mathbf{d t} \mathbf{( s )}$ & 0.145 & 0.145 & 0.15 & 0.155 & 0.165 & 0.19 & 0.205 & 0.225 & 0.28 \\
$\mathbf{V} \mathbf{s e q}_{\text {eq }}(\mathbf{m} / \mathbf{s})$ & 345 & 345 & 333 & 323 & 303 & 263 & 244 & 222 & 179 \\
$\mathbf{V} \mathbf{S e q}_{\text {eqmean }}(\mathbf{m} / \mathbf{s})$ & 350 & 348 & 337 & 324 & 304 & 265 & 245 & 219 & 172 \\
$\mathbf{G}_{\text {eq }}\left(\mathbf{k N} / \mathbf{m}^{\mathbf{2}}\right)$ & 242418 & 242418 & 226526 & 212147 & 187212 & 141187 & 121281 & 100678 & 65011 \\
$\mathbf{I}$ & 1,015 & 1,015 & 1,050 & 1,085 & 1,120 & 1,260 & 1,365 & 1,505 & 1,820 \\
$\mathbf{A}\left(\mathbf{f}_{\mathbf{1}}\right)$ & 1,00 & 1,00 & 1,00 & 1,01 & 1,05 & 1,14 & 1,20 & 1,25 & 1,38 \\
$\mathbf{D}_{\text {eq }}$ & 0,0097 & 0,0097 & 0,0296 & 0,0409 & 0,0403 & 0,0517 & 0,0638 & 0,0878 & 0,1126 \\
$\boldsymbol{\gamma}_{\text {max }}$ & 0,00008 & 0,00081 & 0,00405 & 0,00824 & 0,01737 & 0,05037 & 0,07684 & 0,12101 & 0,30095 \\
$\boldsymbol{\gamma}_{\text {eff }}$ & 0,00005 & 0,00052 & 0,00263 & 0,00535 & 0,01129 & 0,03274 & 0,04994 & 0,07866 & 0,19562 \\
\hline
\end{tabular}

Table 1. Example of $G_{e q} / G_{0^{-}} \gamma$ and $D_{e q} \gamma$ calibration parameters of the equivalent column assuming for the heterogeneous column Seed and Idriss (1970) mean curve for sand and Vucetic and Dobry (1991) PI = 30 curves for silt.

The equivalent decay curves are compared with the corresponding target variation curves of the normalized shear modulus, $\mathrm{G} / \mathrm{G}_{0}$, and damping ratio, $\mathrm{D}$, with shear strain, $\gamma$, adopted for sand (i.e., Seed and Idriss (1970) mean curve) and for silt (i.e., Vucetic and Dobry (1991) PI = 15-30-50 curves) layers in the target column (Figure 2). As expected, the comparison shows that the equivalent decay curves are arranged on average in the median position with respect to the literature curves adopted for the heterogeneous column, corroborating the hypothesis that, in presence of lithostratigraphic successions, even more complex than that studied in the example, that are very common in the geological-technical units defined within the SM studies, the nonlinear variation of the shear modulus 
and the damping ratio could be modelled with good approximation as average value weighted respect the abundance of the considered lithotype within the whole column.
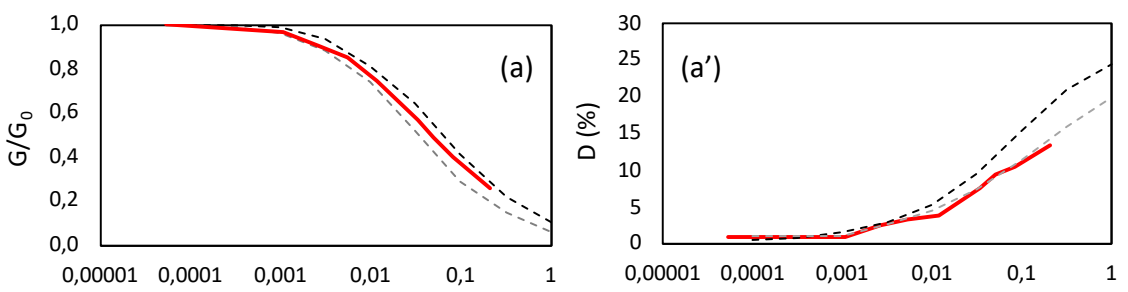

CASE I

SAND: Seed and Idriss (1970) average SILT: Vucetic and Dobry (1991) $\mathrm{PI}=15 \%$

- Equivalent curve

- . - - Seed and idriss (1970) average

Vucetic and Dobry $1991 \mathrm{Pl}=15$
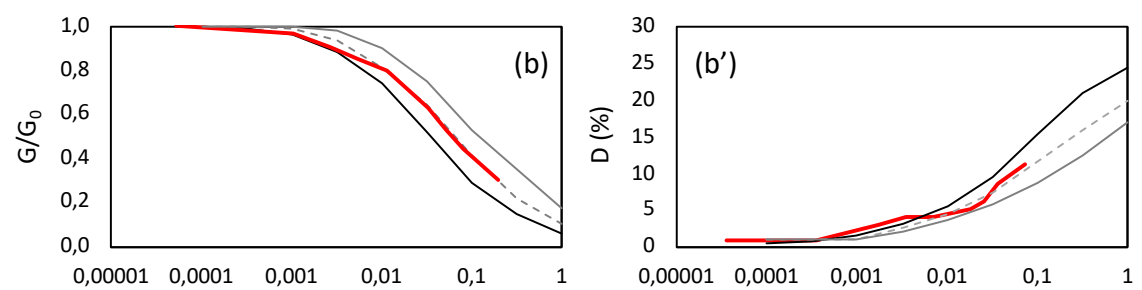

\section{CASE II}

SAND: Seed and Idriss (1970) average SILT: Vucetic and Dobry ( 1991) $\mathrm{Pl}=30 \%$

Equivalent curve

_ Seed and idriss (1970) average

- - - Vucetic and Dobry $1991 \mathrm{Pl}=15$

Vucetic and Dobry $1991 \mathrm{Pl}=30$
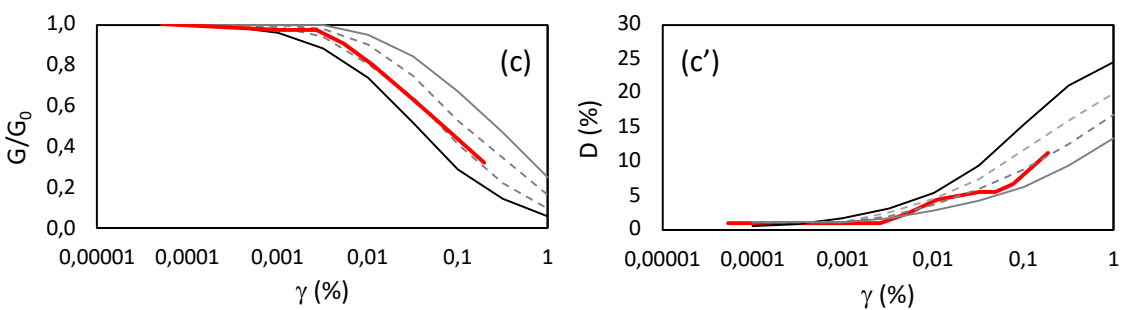

CASE III

SAND: Seed and Idriss (1970) average SILT: Vucetic and Dobry (1991) $\mathrm{PI}=50 \%$

- Equivalent curve

_ Seed and idriss (1970) average

- - - Vucetic and Dobry (1991) PI=15

- - - Vucetic and Dobry (1991) Pl=30

Vucetic and Dobry (1991) Pl=50

Figure 2. Comparison of equivalent the normalized shear modulus and damping ratio curves with the literature curves adopted in the corresponding heterogeneous columns.

A simpler procedure to compute equivalent properties has been then explored with reference to the heterogeneous columns 1 and 2 schematized in Figure 3: both heterogeneous columns were modelled, implementing different sand-silt alternations at depth and assuming the same sand and silt percentage equal to $50 \%$. The sand lithotype was modelled assuming $\mathrm{Vs}_{\mathrm{sand}}=350 \mathrm{~m} / \mathrm{s}, \gamma_{\mathrm{sand}}=20 \mathrm{kN} / \mathrm{m}^{3}$, Seed and Idriss (1970) mean curve, the silt lithotype was modelled assuming V $\mathrm{s}_{\text {silt }}=350 \mathrm{~m} / \mathrm{s}, \gamma_{\text {silt }}=20 \mathrm{kN} / \mathrm{m}^{3}$, Vucetic and Dobry (1991) PI $=30$; the seismic bedrock was modelled assuming V sbedrock $_{1}=800 \mathrm{~m} / \mathrm{s}$, $\gamma_{\text {bedrock }}=20 \mathrm{kN} / \mathrm{m}^{3}$ and $D_{\text {bedrock }}=1 \%$. The seismic response of these heterogeneous columns, subjected to four real earthquakes shown in Figure 3 selected for increased Peak Ground Acceleration (PGA) values and with different frequency content, was compared to the response of equivalent column, subjected to the same input signals and characterized by an equivalent (Vs)eq mean, computed by equation

$$
(\mathrm{Vs})_{\text {eq_mean }}=\frac{\mathrm{H}}{\Sigma \frac{\mathrm{h}_{\mathrm{i}}}{\mathrm{Vs}_{\mathrm{i}}}}
$$

(equal to $350 \mathrm{~m} / \mathrm{s}$ in this case), and $\left(\mathrm{G}_{/} / \mathrm{G}_{0}\right)_{\text {eq }}-\gamma$ and $\left(\mathrm{D}_{\text {eq }}\right)-\gamma$ computed as a weighted average by means the equations

$$
\left(\frac{G}{G_{0}}\right)_{\text {eq }}=\frac{\frac{G}{G_{0}} h_{1}+\frac{G}{G_{0}} h_{2}+\cdots+\frac{G}{G_{0}} h_{n}}{H}
$$

$$
\text { (D) })_{\mathrm{eq}}=\frac{\mathrm{Dh}_{1}+\mathrm{Dh}_{2}+\cdots+D \mathrm{Dh}_{\mathrm{n}}}{\mathrm{H}}
$$


Please note that the equivalent shear wave velocity calculated through the Equation 4 is very close to $\mathrm{Vs}_{\text {,eq }}$ calculated in Equation 1 as ratio between the total column height $\mathrm{H}$ and the travel time, dt, as reported in the Table 1.
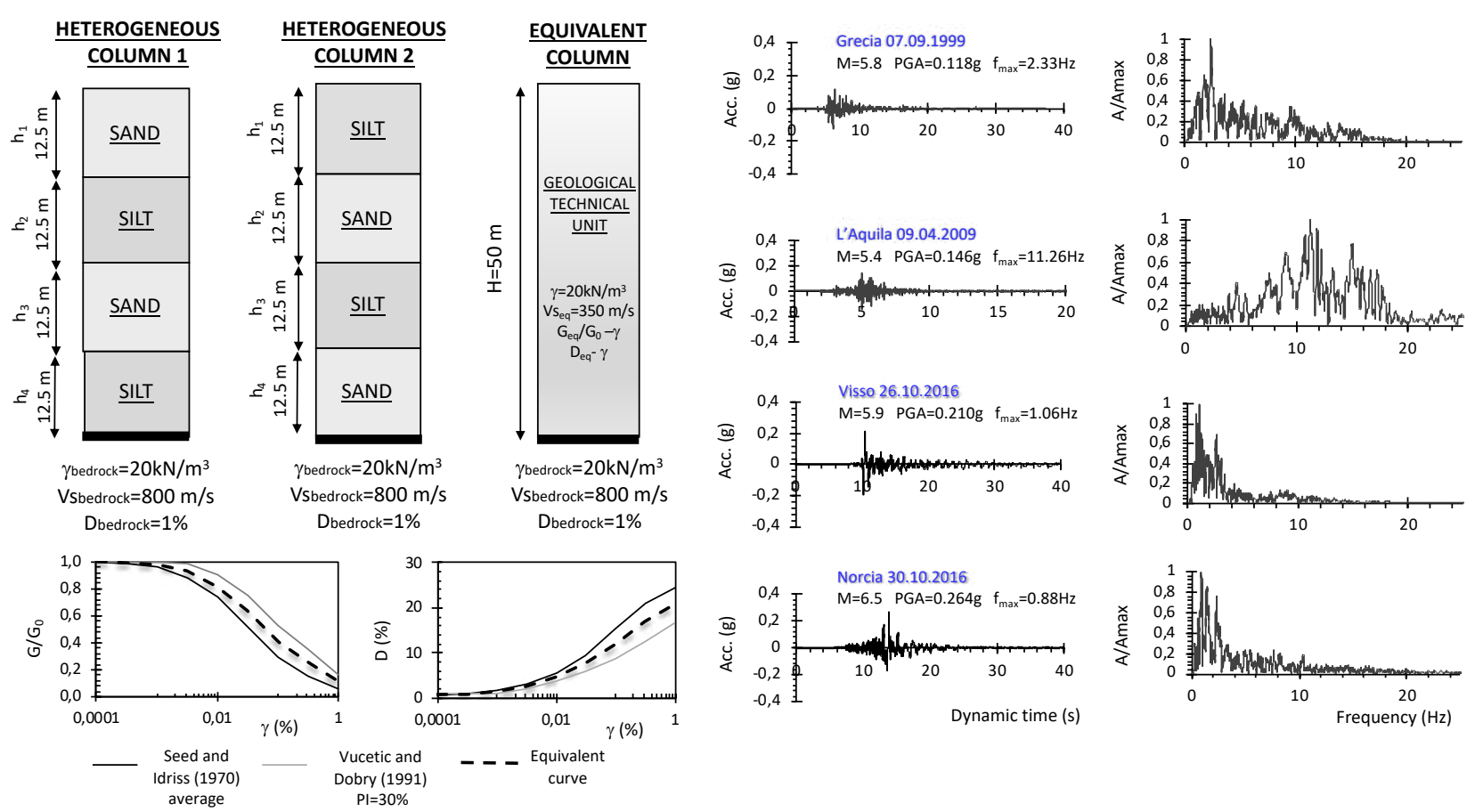

Figure 3. Definition of $1 D$ heterogeneous columns 1 and 2 and the corresponding equivalent one in terms of lithotypes alternation, heterogeneous and equivalent decay curves and input signals.

In order to compare the difference between heterogeneous and equivalent models with uncertainties associated to the approach to include soil nonlinearity, linear equivalent and true nonlinear site response have been executed by means of DEEPSOIL software (Hashash et al., 2017): Figure 4a and Figure $4 \mathrm{~b}$ in particular, show the comparison between nonlinear and equivalent linear analysis for the heterogeneous columns and the corresponding equivalent ones, for the target cases 1 and 2 , respectively.

The comparison was proposed in terms of amplification effects. The ground motion is usually expressed in terms of peak parameters or, more frequently, integral parameters (Pagliaroli, 2018), such as the integral of spectral accelerations or pseudo-velocities in a prescribed range of period. In particular, in SM studies carried out in Italy, amplification effects are generally quantified in terms of the Amplification Factor (AF) over three intervals of vibration periods in the form

$A F_{0.1-0.5}=\frac{\int_{0.1}^{0.5} S a_{o} d T}{\int_{0.1}^{0.5} S a_{i} d T} ; A F_{0.4-0.8}=\frac{\int_{0.4}^{0.8} S a_{o} d T}{\int_{0.4}^{0.8} S a_{i} d T} ; A F_{0.7-1.1}=\frac{\int_{0.7}^{1.1} S a_{o} d T}{\int_{0.7}^{1.1} S a_{i} d T}$

(Pergalani et al., 2019), where the subscripts $i$ and $o$ refer to the reference (input or outcropping bedrock) spectra and to the spectra at soil surface (output) respectively. The AFs are represented by histograms of the average values of the four selected inputs in Figure 4. As a whole, it can be observed a good match between the seismic responses of heterogeneous and the equivalent columns, the differences are in the same order of the uncertainties associated to the analysis method, at least for the considered signals: the equivalent linear approach slightly overestimates the AFs with respect to the nonlinear approach, particularly at low and medium periods, in any case less than $5 \%$, while the difference between the heterogeneous and the equivalent column is contained within $6 \%$. 

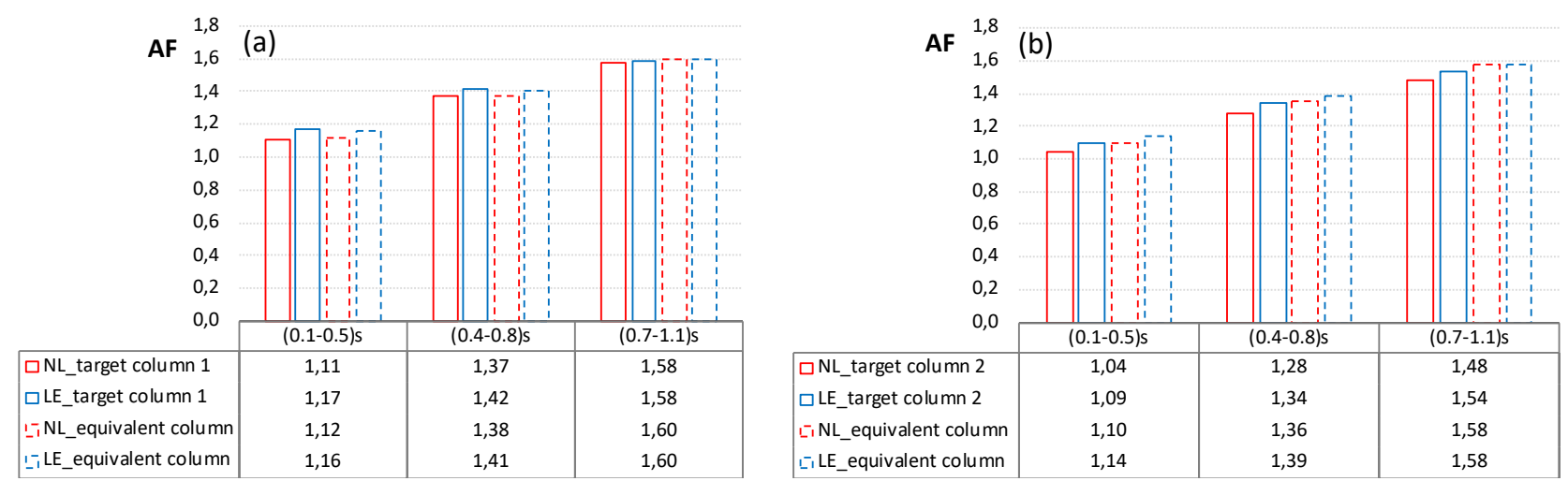

Figure 4. Comparison between (a) the heterogeneous column 1 and (b) the heterogeneous column 2 with the equivalent column in terms of amplification factors for $S M$, in the case of nonlinear and linear equivalent analysis.

The results obtained from this preliminary analysis confirms the possibility to model a 1D column characterized by a generic lithostratigraphic succession with an equivalent one representative of a geological-technical unit within the SM without introducing significative errors.

However, to get more general conclusions, we need to extend this study to a significant number of cases to take into account the high vertical variability typical of the subsoil conditions (Rathje et al., 2010; Kaklamanos et al., 2013; Pagliaroli et al., 2014a,b; Kim et al., 2016; Foti et al., 2019; Fabozzi et al., 2019a, 2019b; 2021). For the scope, an extensive parametric analysis is discussed hereinafter ( $\S 3$ and $\S 4$ ), with reference to the cases of sand-silt and sand-gravel 1D lithostratigraphic successions. Note that the considered lithostratigraphic successions, with reference to the EGU defined within the SM standards (TCSM, 2020, 2021. See Table 2), include most of the cover terrains with exception only of few units (i.e., OL, OH, CH, PT).

\section{EGU from SM}

GW: Well sorted gravels, mixed gravels and sands

GP: Not sorted gravels, mixed gravels and sands

GM: Silty gravels, mixed gravels, sands and silts

GC: Clayey gravels, mixed gravels, sands and clays

SW: Well sorted sands, mixed sands and gravels

SP: Not well sorted sands

SM: Silty sands, mixed sands and silts

SC: Clayey sands, mixed sands and clays

OL: Organic silts, low plasticity organic silty-clays

$\mathrm{OH}$ : Middle plasticity organic clays, organic silts

$\mathrm{MH}$ : Inorganic silts, fine sands, diatomic silts

ML: Inorganic silts, fine silty-clayey sands, low plasticity clayey, silts

CL: Middle-low plasticity inorganic clays, gravel-sandy clays, silty clays

$\mathrm{CH}$ : High plasticity inorganic clays

PT: Peat and organic soils

Table 2. Engineering Geological Units from SM standards (TCSM, 2020, 2021).

\section{PARAMETRIC ANALYSIS}

The parametric study consists in 1D frequency-domain equivalent linear site response analyses carried out by means of numerical simulations. Simulations concern randomly variable vertical lithostratigraphic configurations as conceptually schematized in Figure 5. For a generic lithostratigraphic succession including more than one lithotype, the column is discretized into brick elements (step 2 in Figure 5) by assigning their maximum dimension (10 brick elements $3 \mathrm{~m}$ thick in 
the example in Figure 5). Subsequently, all the possible bricks combinations, defined hereinafter as 'permutations', are generated (step 3 in Figure 5). In particular, starting from the percentage of each lithotype in the lithostratigraphic succession (equal to $10 \%$ for the lithotype 1 and equal to $90 \%$ for the lithotype 2 in the example in Figure 5), all possible not repeated permuted lithostratigraphic successions are simulated by means of the multinomial coefficient expressed as

$$
\left(\begin{array}{l}
n \\
K
\end{array}\right):=\frac{n !}{\prod_{i=1}^{r} k_{i} !}
$$

where $n$ is the total number of bricks and $\boldsymbol{K}$ is the vector representing the bricks number for each considered lithotype.
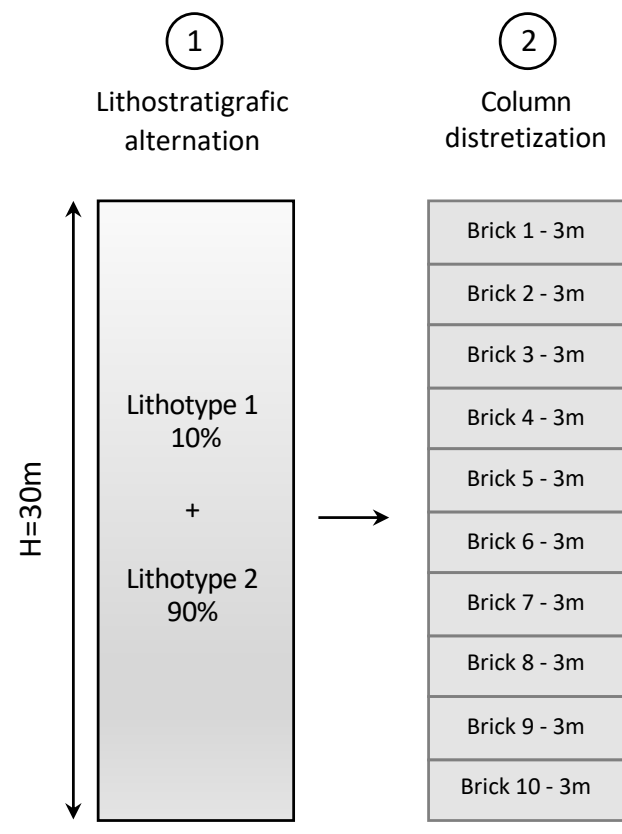

Figure 5. Schematization of NC92soil software generation of permuted columns in presence of a generic lithostratigraphic succession (example case: 10\% for the lithotype 1 and 90\% for the lithotype 2).

Two lithotype combinations in particular, were studied in this work:

1) sand and silt lithostratigraphic successions (Table 3);

2) sand and gravel lithostratigraphic successions (Table 4).

Table 3 and Table 4 synthesize the main properties assigned to the considered combinations. In both cases, 9 combinations were considered, assuming the variation of sand, silt and gravel ranging from $90 \%$ to $10 \%$, setting the shear wave velocity, $\mathrm{Vs}_{\mathrm{i}}$, equal to $250 \mathrm{~m} / \mathrm{s}, 400 \mathrm{~m} / \mathrm{s}$ and $550 \mathrm{~m} / \mathrm{s}$ for silt, sand and gravel, respectively. Note that in the last columns of Tables 3 and 4 the number of permutations computed for each percentage combination are shown: the maximum number of permutations, equal to 252 , is reached when sand, silt and gravel are equal to $50 \%$, while the minimum number of permutations, equal to 10 , is reached when the relative abundance of lithotypes is $90 \%-10 \%$ or $10 \%$ $90 \%$. As example, Figure 6 shows some computed permutations for the combination 5\# (sand 50\% silt 50\%) including complex Vs profiles generated with multiple alternations along the depth. 


\begin{tabular}{|c|c|c|c|c|c|c|c|}
\hline $\begin{array}{l}\text { ID } \\
\#\end{array}$ & $\begin{array}{c}\text { LITHOTYPE } \\
-\end{array}$ & $\begin{array}{c}\text { PERCENTAGE } \\
\%\end{array}$ & $\begin{array}{c}\mathrm{H}_{\mathrm{i}} \\
(\mathrm{m})\end{array}$ & $\begin{array}{l}H_{\text {tot }} \\
\text { (m) }\end{array}$ & $\begin{array}{c}\mathrm{Vs} \mathrm{s}_{\mathrm{i}} \\
(\mathrm{m} / \mathrm{s})\end{array}$ & $\begin{array}{l}\mathrm{Vs}_{\text {eq }} \\
\mathrm{m} / \mathrm{s}\end{array}$ & $\begin{array}{c}\text { NUMBER OF } \\
\text { PERMUTATIONS }\end{array}$ \\
\hline \multirow{2}{*}{1} & sand & 90 & 27 & \multirow{2}{*}{30} & 400 & \multirow{2}{*}{377} & \multirow{2}{*}{10} \\
\hline & silt & 10 & 3 & & 250 & & \\
\hline \multirow{2}{*}{2} & sand & 80 & 24 & \multirow{2}{*}{30} & 400 & \multirow{2}{*}{357} & \multirow{2}{*}{45} \\
\hline & silt & 20 & 6 & & 250 & & \\
\hline \multirow{2}{*}{3} & sand & 70 & 21 & \multirow{2}{*}{30} & 400 & \multirow{2}{*}{339} & \multirow{2}{*}{120} \\
\hline & silt & 30 & 9 & & 250 & & \\
\hline \multirow{2}{*}{4} & sand & 60 & 18 & \multirow{2}{*}{30} & 400 & \multirow{2}{*}{323} & \multirow{2}{*}{210} \\
\hline & silt & 40 & 12 & & 250 & & \\
\hline \multirow{2}{*}{5} & sand & 50 & 15 & \multirow{2}{*}{30} & 400 & \multirow{2}{*}{308} & \multirow{2}{*}{252} \\
\hline & silt & 50 & 15 & & 250 & & \\
\hline \multirow{2}{*}{6} & sand & 40 & 12 & \multirow{2}{*}{30} & 400 & \multirow{2}{*}{294} & \multirow{2}{*}{210} \\
\hline & silt & 60 & 18 & & 250 & & \\
\hline \multirow{2}{*}{7} & sand & 30 & 9 & \multirow{2}{*}{30} & 400 & \multirow{2}{*}{282} & \multirow{2}{*}{120} \\
\hline & silt & 70 & 21 & & 250 & & \\
\hline \multirow{2}{*}{8} & sand & 20 & 6 & \multirow{2}{*}{30} & 400 & \multirow{2}{*}{270} & \multirow{2}{*}{45} \\
\hline & silt & 80 & 24 & & 250 & & \\
\hline \multirow{2}{*}{9} & sand & 10 & 3 & \multirow{2}{*}{30} & 400 & \multirow{2}{*}{260} & \multirow{2}{*}{10} \\
\hline & silt & 90 & 27 & & 250 & & \\
\hline
\end{tabular}

Table 3. Sand-silt lithostratigraphic succession: relative abundance of each lithotype, main properties and number of permutations $\left(H_{i}\right.$ is the cumulative thickness of all the bricks corresponding to the considered lithotypes inside the column, independently from their position; $H_{\text {tot }}$ it the whole height of the column; $V s_{i}$ is the shear wave velocity of each lithotype; $V s$, eq is the equivalent shear wave velocity of the column calculated by means of Equation 4).

\begin{tabular}{|c|c|c|c|c|c|c|c|}
\hline $\begin{array}{l}\text { D } \\
\#\end{array}$ & $\begin{array}{c}\text { LITHOTYPE } \\
- \\
\end{array}$ & $\begin{array}{c}\text { PERCENTAGE } \\
\% \\
\end{array}$ & $\begin{array}{r}\mathrm{H}_{\mathrm{i}} \\
(\mathrm{m})\end{array}$ & $\begin{array}{l}\mathrm{H}_{\text {tot }} \\
(\mathrm{m})\end{array}$ & $\begin{array}{c}V s_{i} \\
(\mathrm{~m} / \mathrm{s})\end{array}$ & $\begin{array}{l}V_{s_{\text {eq }}} \\
(\mathrm{m} / \mathrm{s})\end{array}$ & $\begin{array}{c}\text { NUMBER OF } \\
\text { PERMUTATIONS }\end{array}$ \\
\hline \multirow{2}{*}{1} & sand & 90 & 27 & \multirow{2}{*}{30} & 400 & \multirow{2}{*}{411} & \multirow{2}{*}{10} \\
\hline & gravel & 10 & 3 & & 550 & & \\
\hline \multirow{2}{*}{2} & sand & 80 & 24 & \multirow{2}{*}{30} & 400 & \multirow{2}{*}{423} & \multirow{2}{*}{45} \\
\hline & gravel & 20 & 6 & & 550 & & \\
\hline \multirow{2}{*}{3} & sand & 70 & 21 & \multirow{2}{*}{30} & 400 & \multirow{2}{*}{436} & \multirow{2}{*}{120} \\
\hline & gravel & 30 & 9 & & 550 & & \\
\hline \multirow{2}{*}{4} & sand & 60 & 18 & \multirow{2}{*}{30} & 400 & \multirow{2}{*}{449} & \multirow{2}{*}{210} \\
\hline & gravel & 40 & 12 & & 550 & & \\
\hline \multirow{2}{*}{5} & sand & 50 & 15 & \multirow{2}{*}{30} & 400 & \multirow{2}{*}{463} & \multirow{2}{*}{252} \\
\hline & gravel & 50 & 15 & & 550 & & \\
\hline \multirow{2}{*}{6} & sand & 40 & 12 & \multirow{2}{*}{30} & 400 & \multirow{2}{*}{478} & \multirow{2}{*}{210} \\
\hline & gravel & 60 & 18 & & 550 & & \\
\hline \multirow{2}{*}{7} & sand & 30 & 9 & \multirow{2}{*}{30} & 400 & \multirow{2}{*}{494} & \multirow{2}{*}{120} \\
\hline & gravel & 70 & 21 & & 550 & & \\
\hline \multirow{2}{*}{8} & sand & 20 & 6 & \multirow{2}{*}{30} & 400 & \multirow{2}{*}{512} & \multirow{2}{*}{45} \\
\hline & gravel & 80 & 24 & & 550 & & \\
\hline \multirow{2}{*}{9} & sand & 10 & 3 & \multirow{2}{*}{30} & 400 & \multirow{2}{*}{530} & \multirow{2}{*}{10} \\
\hline & gravel & 90 & 27 & & 550 & & \\
\hline
\end{tabular}

Table 4. Sand-gravel lithostratigraphic succession: relative abundance of each lithotype, main properties and number of permutations $\left(H_{i}\right.$ is the cumulative thickness of all the bricks corresponding to the considered lithotypes inside the column, independently from their position; $H_{\text {tot }}$ it the whole height of the column; $V s_{i}$ is the shear wave velocity of each lithotype; $V s$, eq is the equivalent shear wave velocity of the column calculated by means of Equation 4). 


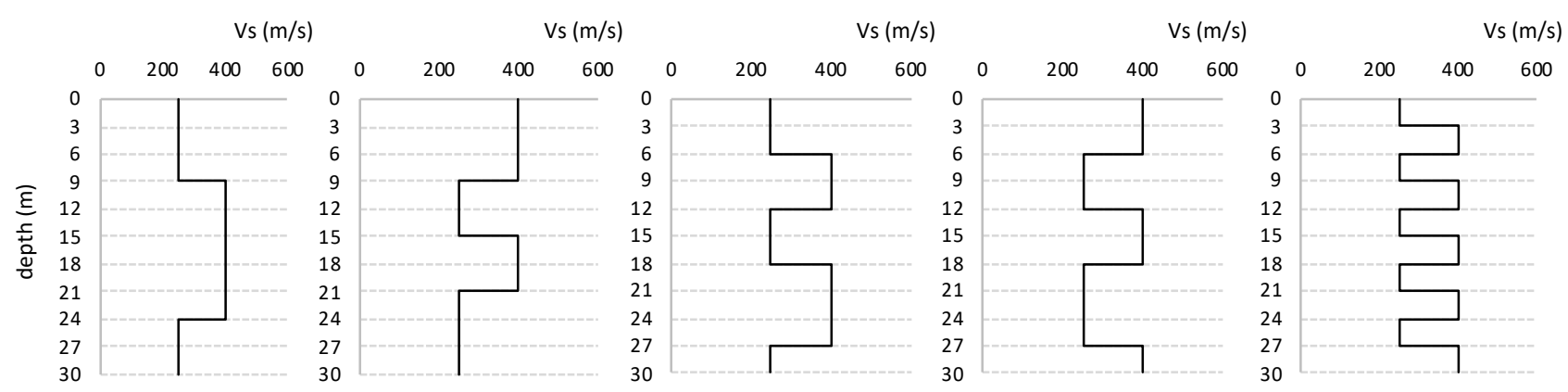

Figure 6. Some example of permutations (5 over 252) generated into the alternation sand 50\% - silt 50\%.

Regarding the nonlinear curves, the variation of the normalized shear modulus, $\mathrm{G}_{\mathrm{G}} \mathrm{G}_{0}$, and damping ratio, D, with shear strain, $\gamma$, has been defined according to the curves by Stokoe et al. (2004) for well-graded gravel (GW), well-graded sand (SW) and low-plasticity clay (CL) resulting from a large number of laboratory tests. As it can be observed in Figure 7 a-a', the selected curves clearly identify the different behavior of the three lithotypes, both in terms of shear modulus decay and damping increment. Other "standard" literature curves do exist: the Stokoe et al. (2004) SW and CL curves well match the well-known Seed and Idriss mean (1970) and Vucetic and Dobry IP $=15$ (1991) ones, respectively; on the contrary Stokoe et al. (2004) GW curve significantly differs from Rollins et al. (1998) curves, frequently used for gravelly soils, that is more linear and very close to Seed and Idriss mean (1970). For our purposes, to assume a more pronounced difference between the cyclic behavior of the two lithotypes (sands and gravels), we preferred Stokoe et al. (2004) GW for gravelly soils. These selected curves were adapted to all equivalent columns representative for each permutation, weighing the percentage contribution of the three considered lithotypes by means of Equations 5 and 6. Figure $7 b-b$ ' and Figure $7 c-c$ ' shows the so calculated equivalent $\left(G / G_{0}\right)_{\text {eq }}-\gamma$ and $\left(D_{\text {eq }}\right)-\gamma$ curves for sand-silt and sand-gravel lithostratigraphic alternation, respectively. Finally, regarding the input signals, three groups of 10 unscaled real accelerograms, for a total of 30 real earthquakes, recorded at outcropping seismic bedrock were selected for three different PGA levels: Class 1 (PGA $\leq 0.1 \mathrm{~g})$, Class $2(0.1 \mathrm{~g}<$ PGA $<0.2 \mathrm{~g})$, Class $3(0.2 \mathrm{~g}<\mathrm{PGA}<0.4 \mathrm{~g})$, respectively. The natural accelerograms were extracted from the Italian database ITACA (http://itaca.mi.ingv.it/), considering as selection criteria: $i$ ) the magnitude ranging from 5 to 7 ; ii) the epicentral distance ranging from $10 \mathrm{~km}$ to $80 \mathrm{~km}$; iii) seismic stations located in correspondence of site class A (based on geophysical tests) or A* (based on surface geology) according to EuroCode 8 (outcropping rock conditions). Tables 5-to-7 show in detail the main characteristics of the selected accelerograms. 

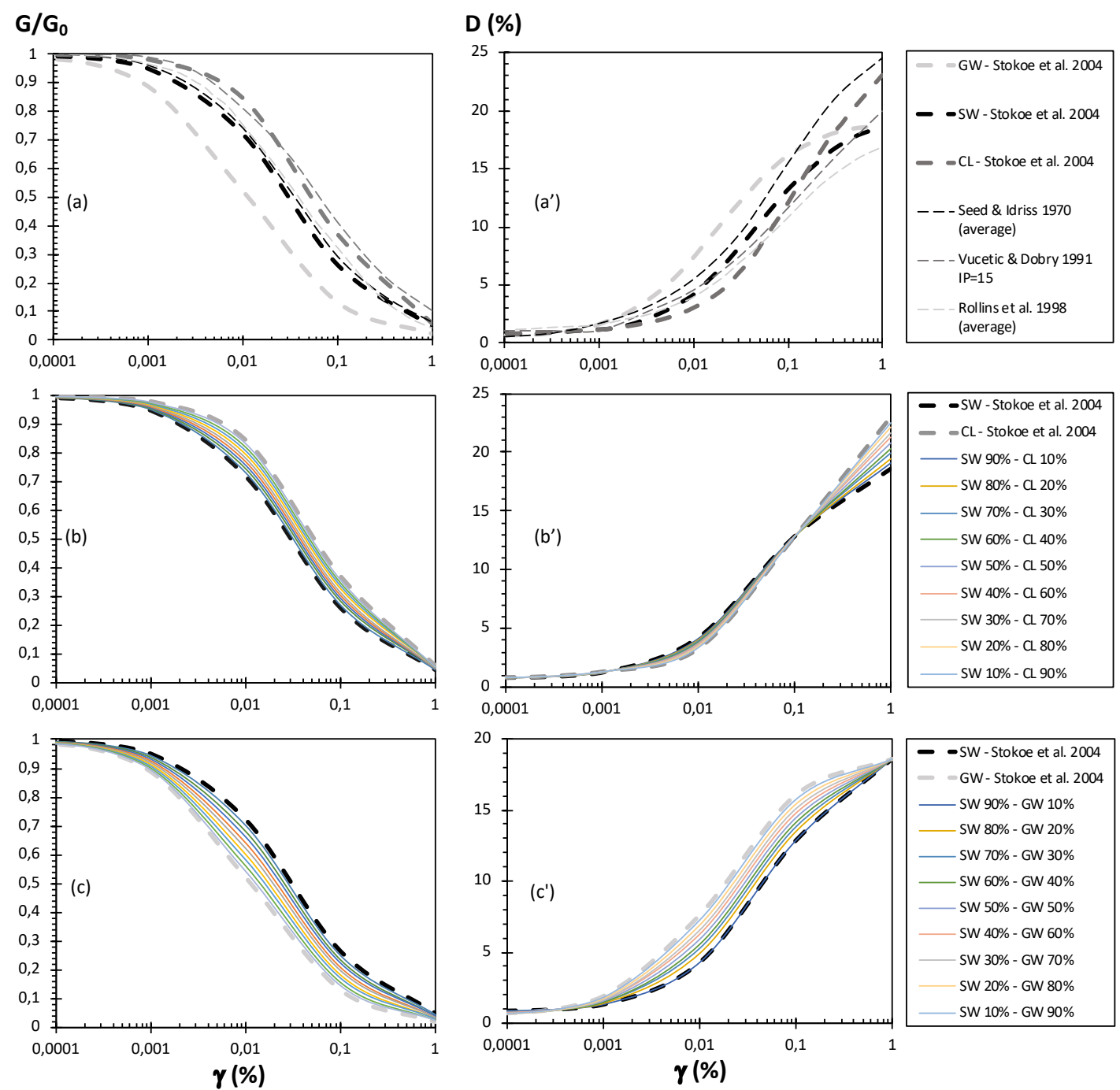

Figure 7. Target variation curves of $\left(a-a^{\prime}\right) G / G_{0-}-\gamma$ and $D / \gamma$ for sand, silt and gravel and equivalent variation curves of $G / G_{0}-\gamma$ and $D / \gamma$ for $\left(b-b^{\prime}\right)$ sand-silt and (c-c') alternations.

\begin{tabular}{|c|c|c|c|c|c|c|c|c|}
\hline $\begin{array}{l}\text { ID } \\
\#\end{array}$ & $\begin{array}{c}\text { EVENT NAME } \\
-\end{array}$ & $\begin{array}{c}\text { DATE } \\
- \\
\end{array}$ & $\begin{array}{c}\text { Mw } \\
-\end{array}$ & $\begin{array}{c}\text { ST. CODE } \\
- \\
\end{array}$ & $\begin{array}{l}\text { EC8 } \\
\text { class }\end{array}$ & $\begin{array}{l}\mathrm{Vs}, 30 \\
(\mathrm{~m} / \mathrm{s})\end{array}$ & $\begin{array}{l}\text { Ep. Dist. } \\
\text { (KM) }\end{array}$ & $\begin{array}{l}\text { PGA } \\
\text { (g) }\end{array}$ \\
\hline 1 & CENTRAL_ITALY & 18.01.2017 & 5,5 & ANT & A & 805 & 21,0 & 0,010 \\
\hline 2 & CENTRAL_ITALY & 18.01.2017 & 5,5 & LSS & A & 1091 & 26,0 & 0,013 \\
\hline 3 & CENTRAL_ITALY & 26.10.2016 & 5,4 & MTR & A & 1024 & 43,8 & 0,017 \\
\hline 4 & CENTRAL_ITALY & 26.10 .2016 & 5,4 & T1211 & $A^{*}$ & - & 47,4 & 0,022 \\
\hline 5 & CENTRAL_ITALY & 30.10 .2016 & 6,5 & GNU & $A^{*}$ & - & 44,3 & 0,039 \\
\hline 6 & CENTRAL_ITALY & 26.10 .2016 & 5,4 & MZ14 & $A^{*}$ & - & 36,6 & 0,057 \\
\hline 7 & CENTRAL_ITALY & 26.10 .2016 & 5,4 & T1212 & $A^{*}$ & - & 18,8 & 0,066 \\
\hline 8 & CENTRAL_ITALY & 24.08.2016 & 6,0 & MTR & A & 1024 & 19,4 & 0,075 \\
\hline 9 & CENTRAL_ITALY & 24.08.2016 & 6,0 & TERO & A & 912 & 31,5 & 0,083 \\
\hline 10 & IRPINIA & 23.11.1980 & 6,9 & BSC & A & 972 & 28,3 & 0,093 \\
\hline
\end{tabular}

Table 5. Selection of input signal for Class 1 ( $P G A \leq 0.1 \mathrm{~g})$. (MW= magnitude; $S T C O D E=$ station code; EC8=site 


\begin{tabular}{|c|c|c|c|c|c|c|c|c|}
\hline $\begin{array}{c}\text { ID } \\
\#\end{array}$ & $\begin{array}{c}\text { EVENT NAME } \\
-\end{array}$ & $\begin{array}{c}\text { DATE } \\
-\end{array}$ & Mw & $\begin{array}{c}\text { ST. CODE } \\
-\end{array}$ & $\begin{array}{l}\text { EC8 } \\
\text { class }\end{array}$ & $\begin{array}{l}\text { Vs,30 } \\
(\mathrm{m} / \mathrm{s})\end{array}$ & $\begin{array}{c}\text { EP. DIST. } \\
\text { (KM) }\end{array}$ & $\begin{array}{r}\text { PGA } \\
\text { (g) }\end{array}$ \\
\hline 11 & SICILY & 13.12.1990 & 5,5 & SRT & A & 871 & 36,9 & 0,105 \\
\hline 12 & CENTRAL_ITALY & 30.10 .2016 & 6,5 & MNF & $A^{*}$ & - & 26,0 & 0,114 \\
\hline 13 & CENTRAL_ITALY & 18.01.2017 (13:33) & 5,0 & RQT & A & 805 & 31,4 & 0,115 \\
\hline 14 & GREECE & 07.09.1999 & 5,9 & ATH4 & A & 1020 & 19,7 & 0,118 \\
\hline 15 & CENTRAL_ITALY & 07.04 .2009 & 5,5 & RM13 & $A^{*}$ & - & 15,6 & 0,130 \\
\hline 16 & CENTRAL_ITALY & 18.01.2017 (10:14) & 5,5 & RQT & A & 805 & 37,9 & 0,137 \\
\hline 17 & SOUTHERN_ITALY & 03.01.1998 & 5,6 & LRS & A & 1024 & 18,0 & 0,161 \\
\hline 18 & CENTRAL_ITALY & 30.10 .2016 & 6,5 & MZ11 & $A^{*}$ & - & 24,8 & 0,165 \\
\hline 19 & CENTRAL_ITALY & 26.10 .2016 & 5,4 & MMO & $A^{*}$ & - & 16,2 & 0,166 \\
\hline 20 & CENTRAL_ITALY & 30.10 .2016 & 6,5 & MMO & $A^{*}$ & - & 19,2 & 0,190 \\
\hline
\end{tabular}

339 Table 6. Selection of input signal for Class $2(0.1 \mathrm{~g}<P G A<0.2 \mathrm{~g})$. (MW= magnitude; ST CODE= station code;

$340 E C 8=$ site class according to EuroCode8; $V s, 30=$ shear wave velocity in the first $30 \mathrm{~m}$ in depth; Ep. Dist=Epicentral

341 Distance; $P G A=$ Peak ground Acceleration).

\begin{tabular}{|c|c|c|c|c|c|c|c|c|}
\hline $\begin{array}{l}\text { ID } \\
\#\end{array}$ & $\begin{array}{c}\text { EVENT NAME } \\
-\end{array}$ & $\begin{array}{c}\text { DATE } \\
-\end{array}$ & $\begin{array}{c}\text { Mw } \\
-\end{array}$ & $\begin{array}{c}\text { ST. CODE } \\
-\end{array}$ & $\begin{array}{l}\text { EC8 } \\
\text { class }\end{array}$ & $\begin{array}{l}\mathrm{Vs}, 30 \\
\text { (m/s) }\end{array}$ & $\begin{array}{l}\text { EP. DIST. } \\
\text { (KM) }\end{array}$ & $\begin{array}{c}\text { PGA } \\
\text { (g) }\end{array}$ \\
\hline 21 & N.W. BALKAN PENINSULA & 15.04.1979 & 6,9 & ULA & $A^{*}$ & - & 19,7 & 0,209 \\
\hline 22 & CENTRAL_ITALY & 30.10 .2016 & 6,5 & MZ14 & $A^{*}$ & - & 30,6 & 0,214 \\
\hline 23 & CENTRAL_ITALY & 26.10 .2016 & 5,4 & CLO & $A^{*}$ & - & 10,8 & 0,215 \\
\hline 24 & CENTRAL_ITALY & 26.10 .2016 & 5,4 & RQT & $A$ & 805 & 16,7 & 0,217 \\
\hline 25 & N.W. BALKAN PENINSULA & 15.04.1979 & 6,9 & HRZ & $A^{*}$ & - & 62,9 & 0,249 \\
\hline 26 & CENTRAL_ITALY & 30.10 .2016 & 6,5 & T1212 & $A^{*}$ & - & 10,5 & 0,274 \\
\hline 27 & GREECE & 15.10.2016 & 5,0 & SRN & A & 1512 & 52,8 & 0,284 \\
\hline 28 & GREECE & 16.10.2016 & 5,5 & SRN & $A$ & 1512 & 55,4 & 0,287 \\
\hline 29 & TURKEY & 13.09.1999 & 5,8 & 4101 & A & 827 & 13,8 & 0,317 \\
\hline 30 & CENTRAL ITALY & 30.10 .2016 & 6,5 & MZ19 & $A^{*}$ & - & 22,6 & 0,356 \\
\hline
\end{tabular}

344 Table 7. Selection of input signal for Class $3(0.2 \mathrm{~g}<P G A<0.4 \mathrm{~g})$. (MW= magnitude; ST CODE= station code; $345 E C 8=$ site class according to EuroCode8; $V s, 30=$ shear wave velocity in the first $30 \mathrm{~m}$ in depth; Ep. Dist=Epicentral 346 Distance; $P G A=$ Peak ground Acceleration).

As it can be observed in Figures 8a,b,c, the considered PGA values are almost uniformly distributed in the three classes, from the lower to the higher extreme of each interval. The frequency content of the input signals is shown in Figures 8a',b',c' in terms of normalized Fourier spectra FA/FA $A_{\text {max }}$ being FA the Fourier Amplitude and FA $_{\max }$ the maximum value of Fourier Amplitude for the considered PGA class. 

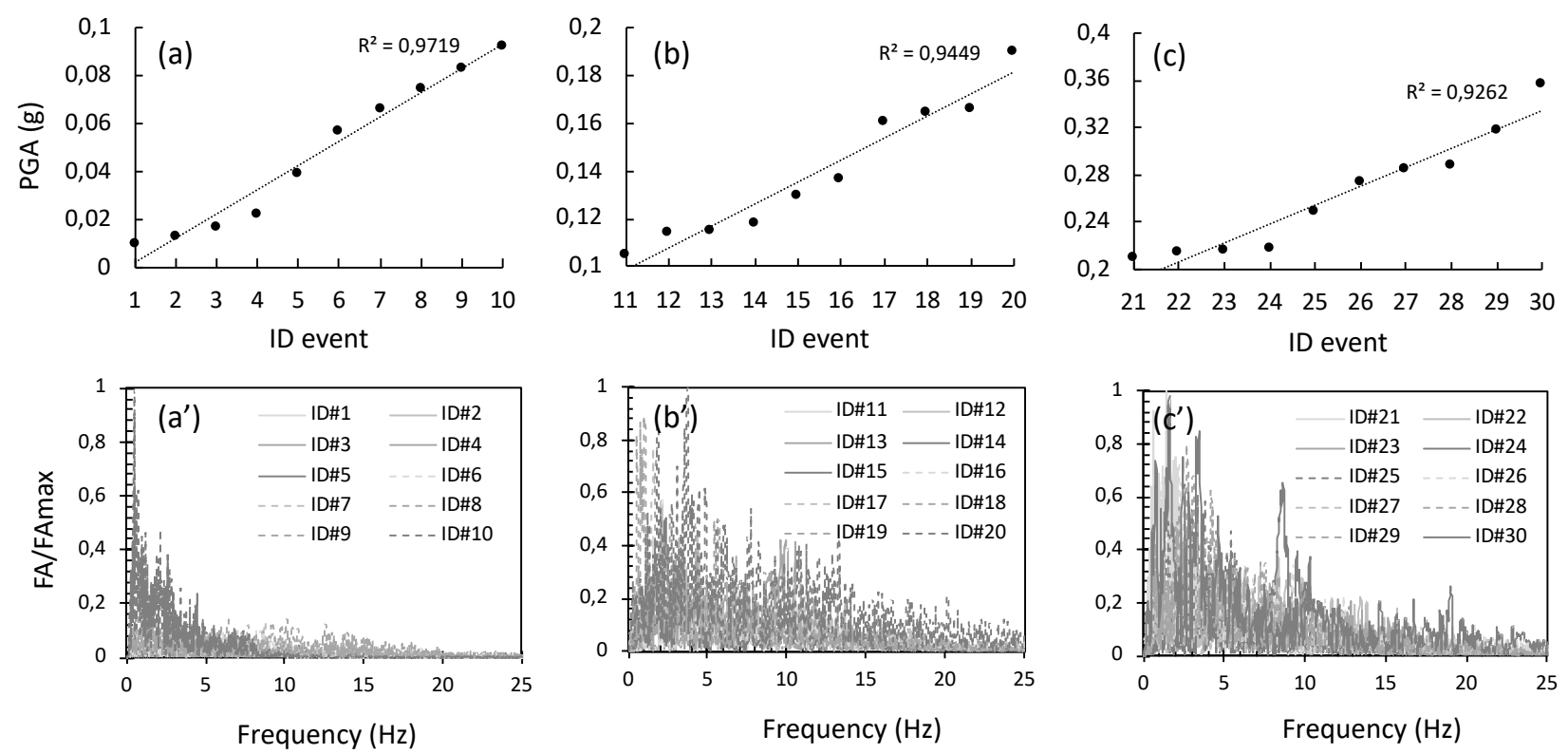

Figure 8. PGA distribution for (a) Class 1 (PGA $\leq 0.1 \mathrm{~g}$ ), (b) Class 2 (0.1 g<PGA<0.2 g), (c) Class 3 (0.2 g < $P G A<0.4 \mathrm{~g})$ and frequency content of the earthquakes for ( $a$ ') Class 1 ( $P G A \leq 0.1 \mathrm{~g})$ normalized by $F A_{\max }=0.197$ g-sec, (b') Class 2 (0.1 g $<P G A<0.2 \mathrm{~g})$ normalized by FA $\max =0.119 \mathrm{~g}$-sec; (c') Class 3 (0.2 g<PGA<0.4 g) normalized by $F A_{\max }=0.177 \mathrm{~g}$-sec.

\section{DISCUSSION OF THE RESULTS}

The outcomes of the parametric analysis were processed in terms of AFs (calculated through the Equation 7) and the fundamental periods $\left(\mathrm{T}_{0}\right)$ of the permutated columns compared with the same parameters associated to equivalent columns. As example, these results are shown in Figure 9 for sand (50\%) - silt (50\%) and sand (50\%) - gravel (50\%) alternations. In Figure 9a,c, the AFs are represented by histograms separately for the three intervals of periods (i.e., [0.1s-0.5s]; [0.4s- $0.8 \mathrm{~s}]$; [0.7s-1.1s]) and the three PGA classes (from light blue to dark blue for the permuted columns and from light to dark orange for the equivalent columns). Each histogram represents the mean value over all the signals falling into the considered PGA class and limited to the permuted columns, they were also averaged with respect to the number of permutations associated with the different percentage combinations between the considered lithotypes (see permutations number in Tables 3 and 4).

Analogously, in Figures 9b,d, the fundamental period of the permuted (orange points) and the equivalent (blue points) columns are compared, once again averaging the values respect the input signals of the PGA classes and the number of permutations. Furthermore, the linear elastic fundamental period calculated as $\mathrm{T}_{\mathrm{el}}=4 \mathrm{H} / \mathrm{Vs}_{\mathrm{eq}}$ is also displayed for comparison (red line).

Due to the nonlinearity, it can be appreciated an increasing trend of the period when the PGA increases. For sand-silt alternations (Figure 9a,b), $\mathrm{T}_{0}$ falls inside the $[0.4 \mathrm{~s}-0.8 \mathrm{~s}]$ range of period thus justifying the higher amplifications observed in this range. Conversely, for sand-gravel alternations (Figure 9c,d), for PGA class 1, most cases fall inside the low interval of period while for the PGA class 2 and 3 most cases fall inside the medium and high intervals of period. Accordingly, the higher AFs are in [0.1s- $0.5 \mathrm{~s}]$ for PGA class 1 and in [0.4s-0.8s] for class 2 and 3. All outcomes obtained for all percentage ratio are shown in the Supplementary Material.

Overall, a satisfactory agreement between the response of the permuted columns and the corresponding equivalent ones is observed, both in terms of $\mathrm{AF}$ and $\mathrm{T}_{0}$. The difference between the permuted and the equivalent columns is quantified in terms of $\Delta A F_{\text {ratio }}$ and $\Delta T_{0 \text { ratio }}$ as expressed by the equations 
$\Delta A F_{\text {ratio }}=\frac{A F_{\text {equivalent column }}-A F_{\text {permuted column }}}{A F_{\text {equivalent column }}} \%$

$\Delta T_{0 \text { ratio }}=\frac{T_{0} \text { equivalent column }-T_{0 \text { permuted column }}}{T_{0 \text { equivalent column }}} \%$

respectively. In particular, Tables 8 and 9 show this percentage ratio for sand-silt and sand-gravel alternations respectively. In the first case (Table 8), it can be appreciated a difference that does not exceed the $6 \%$ both in terms of $\mathrm{AF}$ and $\mathrm{T}_{0}$ while, in the second case (Table 9), this difference is reduced by one order of magnitude (differences lower than $0.6 \%$ ) due to the higher stiffness of the whole column in presence of gravel leading to a less pronounced nonlinear behavior.

(c)

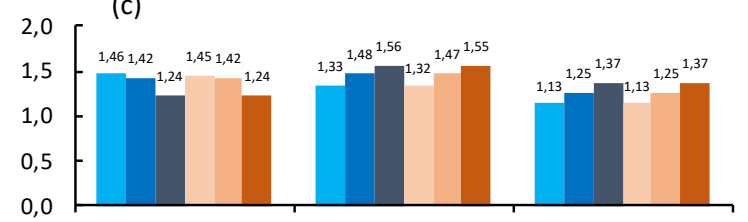

$[0.1-0.5] \mathrm{s}$

Sand $\mathbf{5 0 \%}$ - Silt $\mathbf{5 0 \%}$

(b)

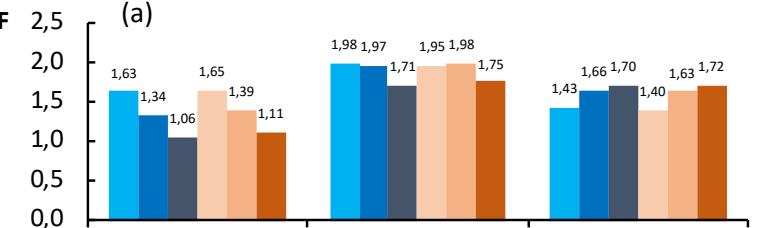

$[0.1-0.5] \mathrm{s}$

$[0.4-0.8] \mathrm{s}$

$[0.7-1.1] \mathrm{s}$

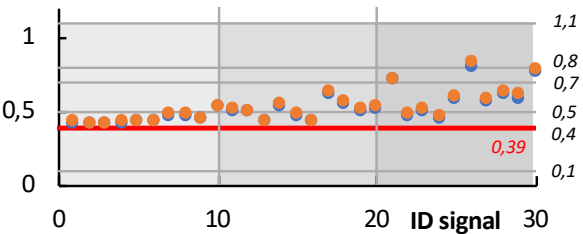

Sand $\mathbf{5 0 \%}$ - Gravel $\mathbf{5 0 \%}$

(d)

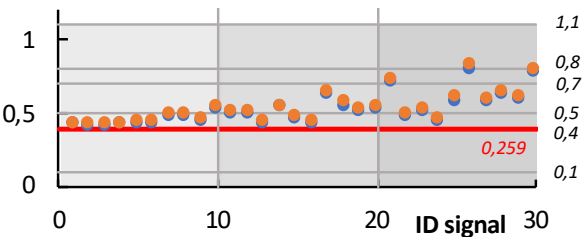

LEGEND:

- Permutations: PGA Class 1 Equivalent column: PGA Class 1

- Permutations: PGA Class 2 Equivalent column: PGA Class 2

LEGEND:

- Permutations: PGA Class 3 Equivalent column: PGA Class 3

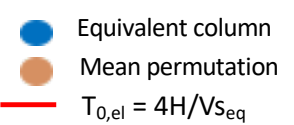

Figure 9. Comparison between permuted and equivalent columns in terms of (a,c) AF and (b,d) $T_{0}$ for sand (50\%) -silt (50\%) and sand (50\%) - gravel (50\%) alternations.

\begin{tabular}{l|c|c|c|c|c}
\hline & PGA & \multicolumn{3}{|c|}{$\Delta$ AF ratio } & $\Delta \mathbf{T}_{\mathbf{0}}$ ratio \\
\cline { 2 - 6 } & class & {$[\mathbf{0 . 1 - 0 . 5 ] \mathbf { s }}$} & {$[\mathbf{0 . 4 - 0 . 8 ] \mathbf { s }}$} & {$[\mathbf{0 . 7 - 1 . 1 ] \mathbf { s }}$} & $\mathbf{s}$ \\
\hline \multirow{3}{*}{ Sand 10\% - Silt 90\% } & 1 & $2 \%$ & $1 \%$ & $-2 \%$ & $-1 \%$ \\
& 2 & $3 \%$ & $3 \%$ & $-1 \%$ & $-1 \%$ \\
& 3 & $3 \%$ & $4 \%$ & $1 \%$ & $-1 \%$ \\
\hline \multirow{3}{*}{ Sand 20\% - Silt 80\% } & 1 & $1 \%$ & $0 \%$ & $-1 \%$ & $-1 \%$ \\
& 2 & $2 \%$ & $1 \%$ & $-1 \%$ & $-1 \%$ \\
& 3 & $2 \%$ & $2 \%$ & $0 \%$ & $-1 \%$ \\
\hline \multirow{3}{*}{ Sand 30\% - Silt 70\% } & 1 & $1 \%$ & $-1 \%$ & $-2 \%$ & $-2 \%$ \\
& 2 & $3 \%$ & $1 \%$ & $-1 \%$ & $-2 \%$ \\
& 3 & $3 \%$ & $2 \%$ & $1 \%$ & $-2 \%$ \\
\hline \multirow{3}{*}{ Sand 40\% - Silt 60\% } & 1 & $1 \%$ & $-1 \%$ & $-2 \%$ & $-2 \%$ \\
& 2 & $3 \%$ & $1 \%$ & $-1 \%$ & $-2 \%$ \\
& 3 & $4 \%$ & $2 \%$ & $1 \%$ & $-2 \%$ \\
\hline \multirow{3}{*}{ Sand 50\% - Silt 50\% } & 1 & $1 \%$ & $-1 \%$ & $-2 \%$ & $-2 \%$ \\
& 2 & $4 \%$ & $1 \%$ & $-2 \%$ & $-2 \%$ \\
& 3 & $5 \%$ & $3 \%$ & $1 \%$ & $-3 \%$ \\
\hline
\end{tabular}




\begin{tabular}{c|c|ccc|c}
\hline \multirow{3}{*}{ Sand 60\% - Silt 40\% } & 1 & $2 \%$ & $-1 \%$ & $-1 \%$ & $-3 \%$ \\
& 2 & $4 \%$ & $1 \%$ & $-1 \%$ & $-3 \%$ \\
& 3 & $6 \%$ & $3 \%$ & $1 \%$ & $-4 \%$ \\
\hline \multirow{3}{*}{ Sand 70\% - Silt 30\% } & 1 & $1 \%$ & $-2 \%$ & $-2 \%$ & $-2 \%$ \\
& 2 & $3 \%$ & $0 \%$ & $-1 \%$ & $-3 \%$ \\
\hline \multirow{3}{*}{ Sand 80\% - Silt 20\% } & 3 & $5 \%$ & $2 \%$ & $0 \%$ & $-4 \%$ \\
\hline \multirow{3}{*}{ Sand 90\% - Silt 10\% } & 1 & $1 \%$ & $-2 \%$ & $-1 \%$ & $-2 \%$ \\
& 2 & $3 \%$ & $0 \%$ & $-1 \%$ & $-2 \%$ \\
& 3 & $5 \%$ & $2 \%$ & $1 \%$ & $-3 \%$ \\
\hline
\end{tabular}

405

406

407

408

Table 8. Comparison between permuted and equivalent columns in terms of $\Delta A F$ ratio and $\Delta T_{0}$ ratio for sand-silt alternations.

\begin{tabular}{|c|c|c|c|c|c|}
\hline & \multirow{2}{*}{$\begin{array}{l}\text { PGA } \\
\text { class }\end{array}$} & \multicolumn{3}{|c|}{$\Delta \mathrm{AF}$ ratio } & \multirow{2}{*}{$\begin{array}{c}\Delta \mathrm{T}_{0} \text { ratio } \\
{[0.1-0.5] \mathrm{s}}\end{array}$} \\
\hline & & {$[0.1-0.5] \mathrm{s}$} & {$[0.4-0.8] \mathrm{s}$} & {$[0.7-1.1] \mathrm{s}$} & \\
\hline \multirow{3}{*}{ Sand $10 \%$ - Gravel $90 \%$} & 1 & $-0,3 \%$ & $-0,1 \%$ & $0,0 \%$ & $-0,05 \%$ \\
\hline & 2 & $-0,3 \%$ & $-0,1 \%$ & $-0,1 \%$ & $0,02 \%$ \\
\hline & 3 & $0,0 \%$ & $-0,2 \%$ & $-0,3 \%$ & $-0,45 \%$ \\
\hline \multirow{3}{*}{ Sand $20 \%$ - Gravel $80 \%$} & 1 & $-0,5 \%$ & $-0,3 \%$ & $-0,1 \%$ & $-0,15 \%$ \\
\hline & 2 & $-0,4 \%$ & $-0,3 \%$ & $-0,2 \%$ & $-0,06 \%$ \\
\hline & 3 & $0,1 \%$ & $-0,3 \%$ & $-0,5 \%$ & $-0,89 \%$ \\
\hline \multirow{3}{*}{ Sand 30\% - Gravel 70\% } & 1 & $-0,6 \%$ & $-0,3 \%$ & $-0,1 \%$ & $-0,02 \%$ \\
\hline & 2 & $-0,4 \%$ & $-0,2 \%$ & $-0,1 \%$ & $0,07 \%$ \\
\hline & 3 & $-0,1 \%$ & $-0,2 \%$ & $-0,4 \%$ & $-0,45 \%$ \\
\hline \multirow{3}{*}{ Sand $40 \%$ - Gravel $60 \%$} & 1 & $-0,7 \%$ & $-0,3 \%$ & $-0,1 \%$ & $-0,18 \%$ \\
\hline & 2 & $-0,5 \%$ & $-0,3 \%$ & $-0,2 \%$ & $0,05 \%$ \\
\hline & 3 & $-0,1 \%$ & $-0,3 \%$ & $-0,5 \%$ & $-0,64 \%$ \\
\hline \multirow{3}{*}{ Sand $50 \%$ - Gravel $50 \%$} & 1 & $-0,7 \%$ & $-0,4 \%$ & $-0,1 \%$ & $-0,13 \%$ \\
\hline & 2 & $-0,5 \%$ & $-0,3 \%$ & $-0,2 \%$ & $0,04 \%$ \\
\hline & 3 & $0,0 \%$ & $-0,3 \%$ & $-0,5 \%$ & $-0,68 \%$ \\
\hline \multirow{3}{*}{ Sand $60 \%$ - Gravel $40 \%$} & 1 & $-0,6 \%$ & $-0,4 \%$ & $-0,2 \%$ & $-0,12 \%$ \\
\hline & 2 & $-0,5 \%$ & $-0,4 \%$ & $-0,2 \%$ & $0,07 \%$ \\
\hline & 3 & $0,0 \%$ & $-0,3 \%$ & $-0,5 \%$ & $-0,74 \%$ \\
\hline \multirow{3}{*}{ Sand 70\% - Gravel 30\% } & 1 & $-0,6 \%$ & $-0,4 \%$ & $-0,2 \%$ & $-0,15 \%$ \\
\hline & 2 & $-0,4 \%$ & $-0,4 \%$ & $-0,2 \%$ & $-0,11 \%$ \\
\hline & 3 & $0,0 \%$ & $-0,3 \%$ & $-0,5 \%$ & $-0,63 \%$ \\
\hline \multirow{3}{*}{ Sand $80 \%$ - Gravel $20 \%$} & 1 & $-0,4 \%$ & $-0,2 \%$ & $-0,1 \%$ & $-0,03 \%$ \\
\hline & 2 & $-0,3 \%$ & $-0,2 \%$ & $-0,1 \%$ & $-0,06 \%$ \\
\hline & 3 & $-0,1 \%$ & $-0,2 \%$ & $-0,3 \%$ & $-0,54 \%$ \\
\hline \multirow{3}{*}{ Sand $90 \%$ - Gravel $10 \%$} & 1 & $-0,2 \%$ & $-0,1 \%$ & $0,0 \%$ & $0,04 \%$ \\
\hline & 2 & $-0,2 \%$ & $-0,1 \%$ & $-0,1 \%$ & $0,01 \%$ \\
\hline & 3 & $0,0 \%$ & $-0,1 \%$ & $-0,1 \%$ & $-0,04 \%$ \\
\hline
\end{tabular}

Table 9. Comparison between permuted and equivalent columns in terms of $\Delta A F$ ratio and $\Delta T_{0}$ ratio for sand-gravel alternations.

A further comparison is finally proposed in Figures 10 and 11. In function of the PGA classes and separately for the three ranges of period, the FA and $\mathrm{T}_{0}$ of the permuted columns (colorful points) are compared with the limit cases in which the permuted columns show a percentage ratio of sand, silt and gravel equal to $100 \%$ (x pointers). These limit cases perfectly bound the variation interval of $\mathrm{AF}$ an $\mathrm{T}_{0}$ of all permutations. Note that the results shown in Figures 10 and 11 are averaged with respect to the number of permutations and the input signals of the considered PGA class. 

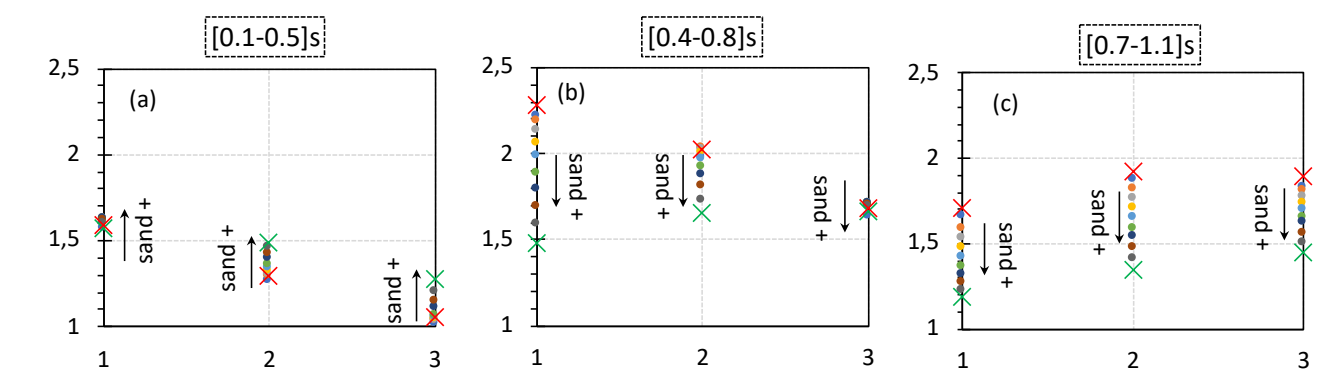

- sand $10 \%$ silt $90 \%$

- sand $20 \%$ silt $80 \%$

- sand $30 \%$ silt $70 \%$

- sand $40 \%$ silt $60 \%$

- sand $50 \%$ silt $50 \%$

- sand $60 \%$ silt $40 \%$

- sand $70 \%$ silt $30 \%$

- sand $80 \%$ silt $20 \%$

- sand $90 \%$ silt $10 \%$

$\times$ sand $100 \%$
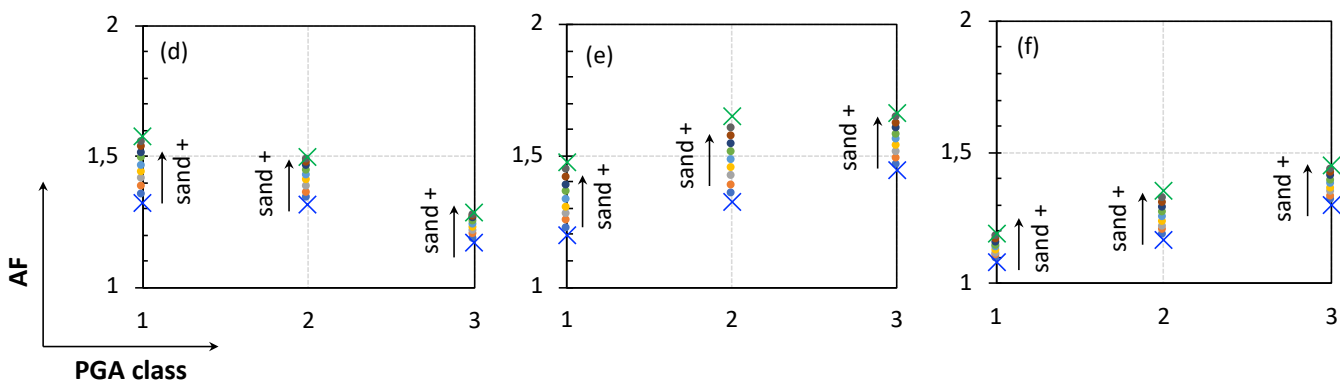

- sand $10 \%$ gravel $90 \%$

- sand $20 \%$ gravel $80 \%$

- sand $30 \%$ gravel $70 \%$

- sand $40 \%$ gravel $60 \%$

- sand $50 \%$ gravel $50 \%$

- sand $60 \%$ gravel $40 \%$

- sand $70 \%$ gravel $30 \%$

- sand $80 \%$ gravel $20 \%$

- sand $90 \%$ gravel $10 \%$

$\times$ sand $100 \%$

Figure 10. Comparison in terms of AF-PGA class between the permuted columns for $(a, b, c)$ sand-silt and $(d, e, f)$ sand-gravel alternations with homogeneous limit cases of sand, silt and gravel.

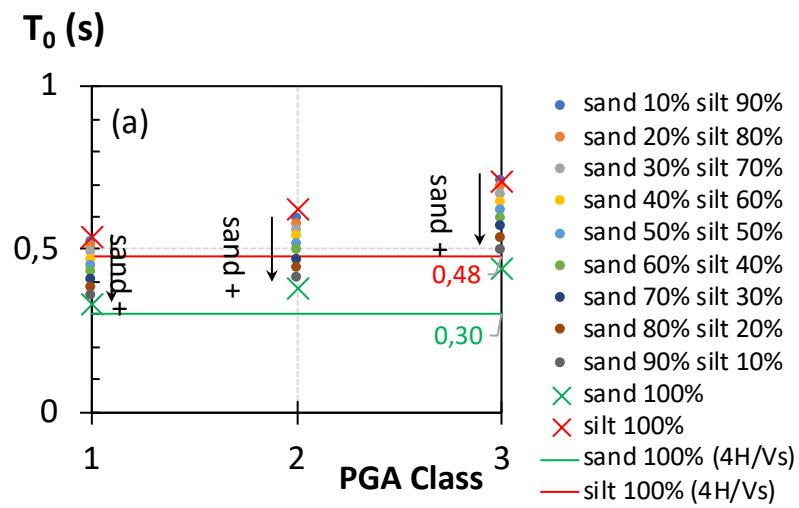

Figure 11. Comparison in terms of $T_{0}-P G A$ class between the permuted columns for (a) sand-silt and (b) sandgravel alternations with homogeneous limit cases of sand, silt and gravel.

\section{CASE STUDY}

An application of the above proposed methodology is here discussed for the site of Mirandola (in Emilia Romagna Region, northern Italy) located on the alluvial deposits of the Po plain; the village suffered significant damages during the 2012 Emilia seismic sequence (Tertulliani et al. 2012). Figure 12a shows the simplified stratigraphic log deducted from Garofalo et al., (2016), characterized mainly by alluvial deposits with alternating sequences of silty-clayey layers of alluvial plain and sandy horizons, for a total depth about equal to $110 \mathrm{~m}$, overlaying the seismic bedrock consisting of marine and transitional deposits of lower-middle Pleistocene age. The stratigraphic log includes also the SM classification where four main geological units were identified with the following percentages: $\mathrm{MH}=18 \% ; \mathrm{CL}=21 \% ; \mathrm{SP}=19 \% ; \mathrm{SW}=42 \%$. The adopted Vs profile shown in Figure $12 \mathrm{~b}$, is consistent with the corresponding profiles obtained from down-hole and cross-hole surveys performed, within the InterPACIFIC project (Garofalo et al., 2016) in areas where the Marnoso-Arenacea formation outcrops. According with the implemented methodology, Stokoe et al. (2004) SW and CL curves were adopted to model the nonlinearity of SP-SW and MH-CL geological units, in the percentage of $61 \%$ and $39 \%$, respectively. The site response of the so defined column was compared with the 
corresponding equivalent column characterized by $\mathrm{Vs}$,eq $=304 \mathrm{~m} / \mathrm{s}$ and equivalent decay curves weighted respect the considered alternation.

Seven input signals recorded on rock outcrop were extracted from the European Strong Motion database (ESMd, https://esm.mi.ingv.it), and scaled up to the reference value of the peak ground acceleration ( PGA $_{\text {ref }}$ ). In particular, according to the probabilistic seismic hazard approach (PSHA), adopted by the Italian Building code (NTC, 2018), the median hazard curve ( $50^{\circ}$ percentile) provides a value of $\mathrm{ag}_{\mathrm{g}}$ about equal to $0.13 \mathrm{~g}$, in correspondence of a return period of $475 \mathrm{y}$. The spectrumcompatibility of the selected signals was achieved by adopting In-Spector REV007 software (Acunzo et al., 2014) in the period range 0.1-1.1s. The procedure required a manual pre-selection of the signals based on the disaggregation histogram of the site; in particular, the selection was set in the ranges of $4<\mathrm{Mw}<7$ and $0<$ Ep.Dist $<60 \mathrm{~km}$, encompassing the whole de-aggregation histogram. In Table 10 are synthesized the main characteristics of the selected accelerograms which average spectrum resulted compatible with the corresponding uniform target spectrum $50^{\circ}$ percentile as shown in Figure 12c. By comparing the seismic response of Mirandola site between the real (or target) and the equivalent column, it can be observed a good agreement in terms of AF as shown in Figure 12d where the histograms are the mean value calculated respect the seven reference input signals. Accordingly, $\Delta A F_{\text {ratio,mean }}$ was also calculated for the three intervals of period: $\Delta A F_{[0.1 \mathrm{~s}-0.5 \mathrm{~s}]}=6.5 \% ; \Delta A F_{[0.4 \mathrm{~s}-}$ $0.8 \mathrm{~s}]=7 \% ; \Delta A F_{[0.7 \mathrm{~s}-1.1 \mathrm{~s}]}=6 \%$. Please also note that the equivalent model provides conservative estimate of the amplification factors as also observed in most sand-silt alternations in parametric analysis (see Table 8). In terms of period instead, it was calculated a value of $\mathrm{T}_{0 \text {,mean }}$ for the real column equal to $0,63 \mathrm{~s}$ and for the equivalent column equal to $0.6 \mathrm{~s}$ that returned a difference between the models in terms of $\Delta T_{0 \text {,mean }}$ about equal to $5 \%$.
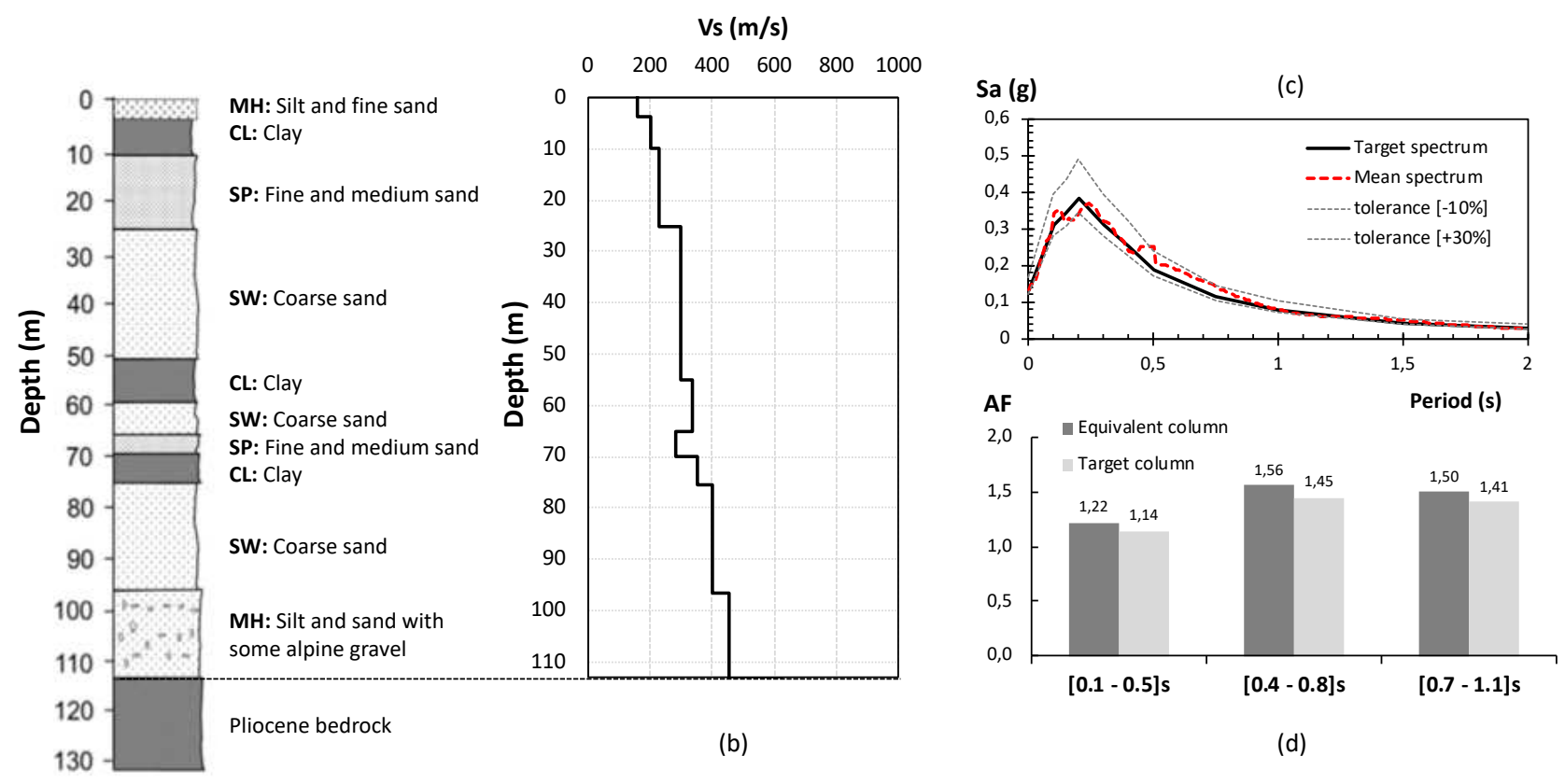

(d)

(a)

Figure 12. Mirandola case study:(a) stratigraphic log (modified after Garofalo et al., 2016); (b) Vs profile (deduced from Garofalo et al., 2016); (c) spectrum compatibility of the input motions; d) AF comparison between the real and the equivalent column. 


\begin{tabular}{|c|c|c|c|c|c|c|c|c|}
\hline $\begin{array}{c}\text { ID } \\
\# \\
\end{array}$ & $\begin{array}{c}\text { EVENT NAME } \\
- \\
\end{array}$ & $\begin{array}{c}\text { DATE } \\
- \\
\end{array}$ & $\begin{array}{c}\text { Mw } \\
- \\
\end{array}$ & $\begin{array}{c}\text { ST. CODE } \\
-\end{array}$ & $\begin{array}{c}\text { EC8 } \\
\text { class }\end{array}$ & $\begin{array}{l}\text { Vs,30 } \\
(\mathrm{m} / \mathrm{s})\end{array}$ & $\begin{array}{c}\text { EP. DIST. } \\
\text { (KM) }\end{array}$ & $\begin{array}{c}\text { PGA }_{\text {ref }} \\
\text { (g) }\end{array}$ \\
\hline 1_MIRANDOLA & SOUTHERN ITALY & 09.09 .1998 & 5.6 & LRS & $A$ & 1024 & 18 & \\
\hline 2_MIRANDOLA & GREECE & 07.09.1999 & 5.9 & ATH4 & $A$ & 1020 & 19.7 & \\
\hline 3_MIRANDOLA & TUKEY & 13.09.1999 & 5.8 & 4101 & $A$ & 827 & 13.8 & \\
\hline 4_MIRANDOLA & CENTRAL_ITALY & 07.04.2009 & 5.1 & $A Q P$ & $A$ & 836 & 5.5 & 0,13 \\
\hline 5_MIRANDOLA & GREECE & 15.10 .2016 & 5.5 & SRN & $A$ & 1512 & 55.4 & \\
\hline 6_MIRANDOLA & CENTRAL_ITALY & 26.10 .2016 & 5.9 & CLO & $A^{*}$ & - & 10.8 & \\
\hline 7_MIRANDOLA & CENTRAL_ITALY & 30.10 .2016 & 6.5 & T1212 & $A^{*}$ & - & 10.5 & \\
\hline
\end{tabular}

Table 10. Selection of input signal for Mirandola site response (MW= magnitude; ST CODE= station code; $E C 8=$ site class according to EuroCode8; Vs,30=shear wave velocity in the first $30 \mathrm{~m}$ in depth; Ep. Dist=Epicentral Distance; $P G A_{\text {ref }}=$ site reference Peak ground Acceleration).

The resulting comparison shows that, although for the case of Mirandola it was considered a deeper column (113m deep) respect the column depth assumed for the parametric analyses ( $30 \mathrm{~m}$ deep), the order of magnitude of the approximation found by modelling the Mirandola real column with the equivalent one is almost the same of the parametric study for the case of sand-silt alternation (§4). Overall, this finding from one hand strengthens the proposal to model the lithostratigraphic alternation with equivalent homogeneous model and, from another hand, demonstrates the possibility to extend this methodology also to column rather deep as for the case of Mirandola site.

\section{CONCLUSIONS}

In the present work, the possibility explored to characterize nonlinear soil behavior of heterogeneous deposits by considering 'equivalent curves' deduced by combining curves relative to the lithotechnical components of the soil deposits. This possibility could be of main importance when fast-and-dirty seismic response evaluations must be extensively determined for heterogeneous soil columns (e.g., lithotypes alternating with depth), which is the case of seismic microzonation studies, in the lack of any detailed geotechnical characterization of each soil component.

The proposal consists in replacing the heterogeneous subsoil model with a homogeneous equivalent one, representative of the Engineering Geological Units (EGU) encountered in the deposit, characterized by the same seismic response at surface (in terms of response spectra and amplification factors). This operation requires the definition of an equivalent shear wave velocity, $\mathrm{Vs}_{\mathrm{s} \text {,eq }}$, and equivalent nonlinear curves of the normalized shear modulus $G_{e q} / G_{0}-\gamma$ and damping ratio $D_{\text {eq }}-\gamma$. The equivalent soil column is characterized in terms of curves corresponding to the weighted average of curves representative of the single components, which is function of its percentual presence.

The outcomes of a wide set of numerical 1D site response analyses, carried for the scope by randomly generating subsoil layering. These simulations, including sequences of alternating thin layers of geotechnical units that cover most of EGU, demonstrate that equivalent homogenous columns and their heterogeneous counterparts provide a seismic response (in terms of amplification and main resonance period) differing not more than $6 \%$ (see Tables 8 and 9). This discrepancy is of the same order of magnitude of that existing when different numerical modelling procedures are applied.

The highest mismatch between the target and the equivalent column was found in sand-silt alternations: this difference is reduced by one order of magnitude (differences lower than $0.6 \%$ ) in the case of sand-gravel alternation due to the higher stiffness of the whole column in presence of gravel leading to a less pronounced nonlinear behavior.

The parametric study discussed above $(\$ 4)$ presents two main limitations in terms of maximum investigated column depth (the maximum depth was set equal to $30 \mathrm{~m}$ in the parametric analysis) and 
in terms of minimum layer thickness (the minimum layer thickness was set equal to $3 \mathrm{~m}$ in the parametric analysis). In order to overcome the limitation related to the maximum investigated column depth, the case study of Mirandola site characterized by a $113 \mathrm{~m}$-thick soil deposit is presented in $\S 5$. The results show that, also for columns deeper that $30 \mathrm{~m}$, the mismatch found by substituting the lithostratigraphic succession with the equivalent column is close to the one found in the parametric study proposed in this work, at least for the case of sand-silt alternation ( $\$ 4)$. This could confirm the possibility to extend this methodology to a wide range of cases.

It remains instead the limitation in terms of minimum layer thickness, although we believe that this hypothesis could not affect very much the forecast of the methodology, also in consideration of the fact that generally, within the Italian SM studies, the degree of detail reached in the description of the stratigraphic successions does not exceed $3 \mathrm{~m}$-thick, as considered in the initial assumption.

Finally, as already mentioned in $\S 1$, the applicability of the proposed methodology is limited to lithostratigraphic alternations exhibiting internal contrast of impedance comparable with ones considered in the present work $(\leq 150 \mathrm{~m} / \mathrm{s})$. Thus it is not applicable in presence of higher contrast of impedance as, for example, in the case of marine and fluvial terraces, alluvial and coastal plains, intermountain basins, cliffs and lava rock layers where the contrast of impedance plays a not negligible rule as observed in Fabozzi et al., 2021.

\section{Acknowledgement}

This research was partially supported by the Italian Civil Protection Department within the project "Contratto concernente l'affidamento di servizi per il programma per il supporto al rafforzamento della Governance in materia di riduzione del rischio sismico e vulcanico ai fini di protezione civile nell'ambito del PON Governance e Capacita Istituzionale 2014-2020 CIG6980737E65" (Massimiliano Moscatelli scientific coordinator).

The authors want to thank Gianluca Acunzo from the Institute of Environmental Geology and Geoengineering of the National Research Council of Italy, author of NC92soil software used in this work. Many thanks for his support.

\section{References}

Acunzo G, Pagliaroli A, Scassera G (2014) In-Spector: un software di supporto alla selezione dei accelerogrammi naturali spettrocompatibili per analisi geotecniche e strutturali. In: $33 \circ$ Convegno Nazionale GNGTS, Bologna 25-27 novembre 2014, vol. 2, pp. 107-114 (ISBN:978-88-940442-25).

Albarello D, Socco VL, Picozzi M, Foti S (2015) Seismic Hazard and land management policies in Italy: the role of seismic investigations. First Break 33:87-93

Albarello D (2017) Extensive application of seismic microzoning: methodological and socio-political issues in the Italian Experience. Boll.Geofis.Teor.Appl.,Vol. 58, n. 4, pp. 253-264, DOI 10.4430/bgta0205

Amanti M, Chiessi V, Muraro C, Puzzilli L, Roma M, Catalano S, Romagnoli G, Tortorici G, Cavuoto G, Albarello D, Fantozzi PL, Paolucci E, Pieruccini P, Caprari P, Mirabella F, Della Seta M, Esposito C, Di Curzio D, Francescone M, Pizzi A, Macerola L, Nocentini M, Tallini M (2020) Geological and geotechnical models definition for 3rd level SM studies in Central Italy. Bull.Earthq.Eng., 18:5441-5473, https://doi.org/10.1007/s10518-020-00843-x

Catalano S, Grassi S, Imposa S, Tortorici G, Cavuoto G, Di Fiore V, Alleanza GA, Chiaradonna A, De Silva F, D'Onofrio A, Silvestri F, Romagnoli G (2019) The subsoil model for seismic microzonation study: The interplay between geology, geophysics and geotechnical engineering -. Earthquake Geotechnical Engineering for Protection and Development of Environment and Constructions-Silvestri \& Moraci (Eds) (C) 2019 Associazione Geotecnica Italiana. Proceeding of 
the VII ICEGE 7th International Conference on Earthquake Geotechnical Engineering, Rome, Italy, 17-20 June, pp 948 - 959. ISBN 978-0-367-14328-2 susceptibility in dry loose sandy and silty soil in a seismic microzonation perspective. Engineering Geology 264 (2020) 105324. https://doi.org/10.1016/j.enggeo.2019.105324.

Fabozzi S, Porchia A, Fierro T, Peronace E, Pagliaroli A, Moscatelli M (2019b) Simplified charts to evaluate settlements from seismic compression in dry loose sand. VII Italian Conference of Researchers in Geotechnical Engineering (CNRIG). Geotechnical Research for Land Protection and Development. Politecnico di Milano Polo territoriale di Lecco, Italy, 3-5 Luglio 2019. In book: Geotechnical Research for Land Protection and Development DOI: 10.1007/978-3-030-21359$6 \_11$.

Fabozzi S, Catalano S, Falcone G, Pagliaroli A, Peronace E, Porchia A, Romagnoli G, Moscatelli M (2021) Stochastic approach to study the site response in presence of shear wave velocity inversion: application to seismic microzonation studies in Italy. Engineering Geology 280 (2021) 105914 https://doi.org/10.1016/j.enggeo.2020.105914.

Foti S, Passeri F, Rodriguez-Marek A (2019) Uncertainties and variabilities in seismic ground response analyses. VII International Conference on Earthquake Geotechnical Engineering. Earthquake Geotechnical Engineering for Protection and Development of Environment and Constructions. Rome, Italy, ISBN 978-0-367-14328-2.

Garofalo F, Foti S, Hollender F, Bard PY, Cornou C, Cox BR, Dechamp A, Ohrnberger M, Perron V, Sicilia D, Teague D, Vergniault C (2016) InterPACIFIC project: Comparison of invasive and non-invasive methods for seismic site characterization. Part II: Inter-comparison between surfacewave and borehole methods. Soil Dynamics and Earthquake Engineering 82 (2016) 241-254

Hashash YMA, Phillips C, Groholski DR (2010) Recent advances in non-linear site response analysis. $5^{\text {th }}$ Int. Conf. in Recent Advances in Geotechnical Earthquake Engineering and Soil Dynamics, Missouri Univ. of Science and Technology, Rolla, MO

Hashash YMA, Musgrove MI, Harmon JA, Ilhan O, Groholski DR, Phillips CA, Park D (2017) DEEPSOIL 7.0, User Manual.

Kaklamanos J, Bradley B.A, Thompson E M, Baise L G (2013) Critical parameters affecting bias and variability in site-response analyses using KiK-net downhole array data. Bulletin of the Seismological Society of America, 103, 1733-1749.

Kim B, Hashash YMA, Stewart JP, Rathje EM, Harmon JA, Musgrove MI, Campbell KW, Silva W J (2016) Relative Differences between Nonlinear and Equivalent- Linear 1-D Site Response Analyses. Earthquake Spectra, 32(3), 1845-1865.

Kramer SL (1996) Geotechnical earthquake engineering. Prentice Hall, New Jersey 653

Moscatelli M, Albarello D, Scarascia Mugnozza G, Dolce M (2020) The Italian approach to seismic microzonation. Bull Earthquake Eng 18, 5425-5440. https://doi.org/10.1007/s10518-020-00856-6

NTC (2018) CS.LL.PP. Decreto Ministeriale: norme tecniche per le costruzioni. Gazz. Uff. della Repubb. Ital. n. 42, 20 febbraio, Suppl. Ordin. n. 8. Ist. Polig. Rome e Zecca dello Stato S.p.a.

Pagliaroli A, Lanzo G, Tommasi P, Di Fiore V (2014a) Dynamic characterization of soils and soft rocks of the Central Archeological Area of Rome. Bull Earthquake Eng (2014) 12:1365-1381 DOI 10.1007/s10518-013-9452-5.

Pagliaroli A, Moscatelli M, Raspa G, Naso G (2014b) Seismic microzonation of the Central Archaeological Area of Rome: results and uncertainties. Bull Earthquake Eng (2014) 12:14051428. doi:10.1007/s10518-013-9480-1.

Pagliaroli A (2018) Key issues in Seismic Microzonation studies: lessons from recent experiences in Italy. Rivista Italiana di Geotecnica - Italian Geotechnical Journal, n. 1/2018, pp. 5-48, DOI: 10.19199/2018.1.0557-1405.05.

Pergalani F, Pagliaroli A, Bourdeau C, Compagnoni M, Lenti L, Lualdi M, Madiai C, Martino S, Razzano R, Varone C, Verrubbi V (2020) Seismic microzoning map: approaches, results and 
applications after the 2016-2017 Central Italy seismic sequence. Bulletin of Earthquake Engineering 18, 5595-5629, DOI: 10.1007/s10518-019-00640-1.

Rathje EM, Kottke AR, Trent WL (2010) Influence of input motion and site property variabilities on seismic site response analysis. Journal of geotechnical and geoenvironmental engineering 136:607619.

Rollins KM, Evans MD, Diehl III, NB, W.D.D (1998) Shear modulus and damping relationships for gravels. J. Geotech. Geoenviron. 124, 396-405. https://doi.org/ 10.1061/(ASCE)10900241(1998)124:5(396).

Seed HB, Idriss IM, (1970) Soil Moduli and Damping Factors for Dynamic Response Analyses. https://ntrl.ntis.gov/NTRL/dashboard/searchResults/titleDetail/PB197 869.xhtml.

Stokoe KH, Darendeli MB, Menq FY, Choi WK (2004) Comparison of the Linear and nonlinear dynamic properties of Gravels, Sands and Clays. Proc. 11th Int. Conf. on Soil Dynamics and Earthquake Engineering (ICSDEE) and 3rd Int. Conf. on Geotechnical Engineering (ICEGE), University of California, Berkeley (USA), 7-9 Gennaio 2004, Doolin et al. (eds), Stallion Press, Singapore.

TCSM (2020) Technical Commission for Seismic Microzonation. Graphic and Data Archiving Standards. Version 4.2 (in Italian). National Department of Civil Protection. Rome. https://www.centromicrozonazionesismica.it/it/download/category/38-standardms-42

TCSM (2021) Technical Commission for Seismic Microzonation. Guidelines for the realization of the engineering geological map for seismic microzonation (in Italian "Linee guida per la realizzazione della Carta Geologico-Tecnica per la Microzonazione Sismica con adattamento ai contesti vulcanici. Versione 1.0"). National Department of Civil Protection. Rome.

http://www.protezionecivile.gov.it/documents/20182/0/LG+per+la+realizzazione+della+CGT$\mathrm{MS}+$ con+adattamento+ai+contesti+vulcanici+vers_1.0/fc705ef2-497d-47cf-ae97393dace88e83Vucetic, M., Dobry, R., 1991. Effect of Soil Plasticity on Cyclic Response. J. Geotech. Eng. 117, 89-107. https://doi.org/10.1061/(ASCE)0733-9410(1991)117:1(89).

Tertulliani A, Arcoraci L, Berardi M, Bernardini F, Brizuela B, Castellano C, Del Mese S, Ercolani E, Graziani L, Maramai A, Rossi A, Sbarra M, Vecchi M (2012) The Emilia 2012 sequence: a macro-seismic survey. Ann Geophys 55:4. doi:10.4401/ag-6140. 
Supplementary materials

\begin{tabular}{|c|c|c|c|c|c|c|}
\hline \multirow{2}{*}{$\begin{array}{l}\text { PGA } \\
\text { class }\end{array}$} & \multicolumn{3}{|c|}{ Permutations } & \multicolumn{3}{|c|}{ Equivalent column } \\
\hline & {$[0.1-0.5] \mathrm{s}$} & {$[0.4-0.8] \mathrm{s}$} & {$[0.7-1.1] \mathrm{s}$} & {$[0.1-0.5] \mathrm{s}$} & {$[0.4-0.8] \mathrm{s}$} & {$[0.7-1.1] \mathrm{s}$} \\
\hline \multicolumn{7}{|c|}{ AF (sand $10-$ silt 90\%) } \\
\hline 1 & 1,58 & 2,22 & 1,67 & 1,61 & 2,23 & 1,64 \\
\hline 2 & 1,27 & 1,97 & 1,88 & 1,31 & 2,04 & 1,87 \\
\hline 3 & 1,02 & 1,63 & 1,83 & 1,06 & 1,70 & 1,85 \\
\hline \multicolumn{7}{|c|}{ AF (sand $20-$ silt $80 \%$ ) } \\
\hline 1 & 1,61 & 2,19 & 1,59 & 1,63 & 2,18 & 1,58 \\
\hline 2 & 1,30 & 2,03 & 1,82 & 1,32 & 2,05 & 1,81 \\
\hline 3 & 1,04 & 1,70 & 1,82 & 1,07 & 1,72 & 1,82 \\
\hline \multicolumn{7}{|c|}{ AF (sand $30-$ silt 70\%) } \\
\hline 1 & 1,62 & 2,13 & 1,54 & 1,64 & 2,12 & 1,51 \\
\hline 2 & 1,31 & 2,02 & 1,77 & 1,34 & 2,04 & 1,75 \\
\hline 3 & 1,04 & 1,70 & 1,78 & 1,08 & 1,74 & 1,79 \\
\hline \multicolumn{7}{|c|}{ AF (sand $40-$ silt $60 \%$ ) } \\
\hline 1 & 1,63 & 2,06 & 1,48 & 1,65 & 2,04 & 1,45 \\
\hline 2 & 1,32 & 2,00 & 1,71 & 1,36 & 2,02 & 1,69 \\
\hline 3 & 1,04 & 1,71 & 1,74 & 1,09 & 1,75 & 1,75 \\
\hline \multicolumn{7}{|c|}{ AF (sand $50-$ silt $50 \%$ ) } \\
\hline 1 & 1,63 & 1,98 & 1,43 & 1,65 & 1,95 & 1,40 \\
\hline 2 & 1,34 & 1,97 & 1,66 & 1,39 & 1,98 & 1,63 \\
\hline 3 & 1,06 & 1,71 & 1,70 & 1,11 & 1,75 & 1,72 \\
\hline \multicolumn{7}{|c|}{ AF (sand $60-$ silt $40 \%)$} \\
\hline 1 & 1,62 & 1,88 & 1,37 & 1,65 & 1,86 & 1,35 \\
\hline 2 & 1,36 & 1,92 & 1,59 & 1,42 & 1,93 & 1,58 \\
\hline 3 & 1,07 & 1,70 & 1,65 & 1,14 & 1,75 & 1,67 \\
\hline \multicolumn{7}{|c|}{ AF (sand $70-$ silt $30 \%$ ) } \\
\hline 1 & 1,63 & 1,79 & 1,32 & 1,64 & 1,76 & 1,30 \\
\hline 2 & 1,40 & 1,87 & 1,54 & 1,45 & 1,87 & 1,52 \\
\hline 3 & 1,11 & 1,71 & 1,63 & 1,17 & 1,75 & 1,63 \\
\hline \multicolumn{7}{|c|}{ AF (sand $80-$ silt 20\%) } \\
\hline 1 & 1,62 & 1,69 & 1,28 & 1,63 & 1,66 & 1,26 \\
\hline 2 & 1,43 & 1,81 & 1,48 & 1,47 & 1,80 & 1,46 \\
\hline 3 & 1,15 & 1,69 & 1,56 & 1,21 & 1,74 & 1,57 \\
\hline \multicolumn{7}{|c|}{ AF (sand $90-$ silt 10\%) } \\
\hline 1 & 1,60 & 1,58 & 1,23 & 1,61 & 1,57 & 1,22 \\
\hline 2 & 1,46 & 1,73 & 1,41 & 1,49 & 1,72 & 1,40 \\
\hline 3 & 1,21 & 1,68 & 1,51 & 1,24 & 1,71 & 1,52 \\
\hline
\end{tabular}




\begin{tabular}{|c|c|c|c|c|c|c|c|c|c|c|}
\hline $\begin{array}{l}\text { ID } \\
\text { signal }\end{array}$ & Perm. & $\begin{array}{l}\text { Eq. } \\
\text { col }\end{array}$ & Perm. & $\begin{array}{l}\text { Eq. } \\
\text { col }\end{array}$ & Perm. & $\begin{array}{l}\text { Eq. } \\
\text { col }\end{array}$ & Perm. & $\begin{array}{l}\text { Eq. } \\
\text { col }\end{array}$ & Perm. & $\begin{array}{l}\text { Eq. } \\
\text { col }\end{array}$ \\
\hline & \multicolumn{2}{|c|}{$\begin{array}{c}\mathrm{T}_{0} \\
\text { (sand 10- silt 90\%) }\end{array}$} & \multicolumn{2}{|c|}{$\begin{array}{c}\mathrm{T}_{0} \\
\text { (sand 20- silt 80\%) }\end{array}$} & \multicolumn{2}{|c|}{$\begin{array}{c}\mathrm{T}_{0} \\
\text { (sand } 30-\text { silt } 70 \% \text { ) }\end{array}$} & \multicolumn{2}{|c|}{$\begin{array}{c}\mathrm{T}_{0} \\
\text { (sand } 40-\text { silt } 60 \% \text { ) }\end{array}$} & \multicolumn{2}{|c|}{$\begin{array}{c}\mathrm{T}_{0} \\
\text { (sand } 50-\text { silt 50\% }\end{array}$} \\
\hline 1 & 0,493 & 0,491 & 0,477 & 0,474 & 0,459 & 0,453 & 0,441 & 0,436 & 0,422 & 0,416 \\
\hline 2 & 0,482 & 0,479 & 0,467 & 0,463 & 0,450 & 0,445 & 0,433 & 0,427 & 0,414 & 0,406 \\
\hline 3 & 0,491 & 0,489 & 0,474 & 0,471 & 0,457 & 0,451 & 0,438 & 0,432 & 0,419 & 0,412 \\
\hline 4 & 0,490 & 0,488 & 0,474 & 0,471 & 0,457 & 0,451 & 0,440 & 0,433 & 0,422 & 0,415 \\
\hline 5 & 0,498 & 0,496 & 0,482 & 0,479 & 0,466 & 0,463 & 0,450 & 0,445 & 0,432 & 0,427 \\
\hline 6 & 0,501 & 0,498 & 0,484 & 0,480 & 0,466 & 0,462 & 0,448 & 0,443 & 0,430 & 0,423 \\
\hline 7 & 0,562 & 0,557 & 0,543 & 0,535 & 0,523 & 0,512 & 0,502 & 0,491 & 0,480 & 0,465 \\
\hline 8 & 0,572 & 0,569 & 0,552 & 0,546 & 0,531 & 0,518 & 0,508 & 0,496 & 0,484 & 0,468 \\
\hline 9 & 0,530 & 0,525 & 0,512 & 0,506 & 0,493 & 0,479 & 0,473 & 0,458 & 0,452 & 0,438 \\
\hline 10 & 0,613 & 0,607 & 0,594 & 0,589 & 0,576 & 0,565 & 0,557 & 0,546 & 0,535 & 0,522 \\
\hline 11 & 0,601 & 0,594 & 0,579 & 0,569 & 0,556 & 0,546 & 0,532 & 0,518 & 0,508 & 0,493 \\
\hline 12 & 0,580 & 0,577 & 0,563 & 0,557 & 0,545 & 0,535 & 0,525 & 0,515 & 0,504 & 0,491 \\
\hline 13 & 0,501 & 0,500 & 0,484 & 0,482 & 0,468 & 0,465 & 0,451 & 0,445 & 0,433 & 0,427 \\
\hline 14 & 0,616 & 0,611 & 0,601 & 0,594 & 0,584 & 0,573 & 0,566 & 0,554 & 0,546 & 0,532 \\
\hline 15 & 0,554 & 0,550 & 0,536 & 0,529 & 0,517 & 0,506 & 0,497 & 0,482 & 0,476 & 0,460 \\
\hline 16 & 0,504 & 0,503 & 0,487 & 0,485 & 0,469 & 0,465 & 0,452 & 0,448 & 0,434 & 0,429 \\
\hline 17 & 0,707 & 0,706 & 0,693 & 0,683 & 0,676 & 0,661 & 0,655 & 0,640 & 0,632 & 0,621 \\
\hline 18 & 0,673 & 0,666 & 0,649 & 0,640 & 0,623 & 0,607 & 0,596 & 0,577 & 0,567 & 0,546 \\
\hline 19 & 0,595 & 0,594 & 0,577 & 0,573 & 0,559 & 0,550 & 0,539 & 0,529 & 0,518 & 0,503 \\
\hline 20 & 0,620 & 0,616 & 0,598 & 0,589 & 0,576 & 0,561 & 0,554 & 0,539 & 0,532 & 0,518 \\
\hline 21 & 0,834 & 0,827 & 0,807 & 0,803 & 0,778 & 0,773 & 0,748 & 0,745 & 0,716 & 0,712 \\
\hline 22 & 0,554 & 0,546 & 0,534 & 0,525 & 0,517 & 0,506 & 0,499 & 0,488 & 0,480 & 0,465 \\
\hline 23 & 0,615 & 0,611 & 0,593 & 0,585 & 0,569 & 0,561 & 0,545 & 0,532 & 0,518 & 0,500 \\
\hline 24 & 0,535 & 0,529 & 0,514 & 0,506 & 0,494 & 0,482 & 0,475 & 0,463 & 0,456 & 0,443 \\
\hline 25 & 0,707 & 0,700 & 0,684 & 0,677 & 0,658 & 0,645 & 0,629 & 0,611 & 0,597 & 0,577 \\
\hline 26 & 0,915 & 0,910 & 0,896 & 0,890 & 0,875 & 0,853 & 0,852 & 0,827 & 0,827 & 0,795 \\
\hline 27 & 0,651 & 0,646 & 0,635 & 0,627 & 0,618 & 0,606 & 0,601 & 0,587 & 0,583 & 0,566 \\
\hline 28 & 0,738 & 0,735 & 0,716 & 0,712 & 0,691 & 0,683 & 0,665 & 0,653 & 0,637 & 0,621 \\
\hline 29 & 0,687 & 0,683 & 0,668 & 0,661 & 0,650 & 0,640 & 0,630 & 0,621 & 0,608 & 0,585 \\
\hline 30 & 0,862 & 0,862 & 0,844 & 0,836 & 0,826 & 0,819 & 0,806 & 0,795 & 0,784 & 0,766 \\
\hline
\end{tabular}

672

673

\begin{tabular}{|c|c|c|c|c|c|c|c|c|}
\hline $\begin{array}{c}\text { ID } \\
\text { signal }\end{array}$ & Perm. & $\begin{array}{c}\text { Eq. } \\
\text { col }\end{array}$ & Perm. & $\begin{array}{c}\text { Eq. } \\
\text { col }\end{array}$ & Perm. & $\begin{array}{c}\text { Eq. } \\
\text { col }\end{array}$ & Perm. & $\begin{array}{c}\text { Eq. } \\
\text { col }\end{array}$ \\
\hline & \multicolumn{2}{|c|}{$\mathbf{T}_{\mathbf{0}}$} & \multicolumn{2}{|c|}{$\mathbf{T}_{\mathbf{0}}$} & \multicolumn{2}{c|}{$\mathbf{T}_{\mathbf{0}}$} & \multicolumn{2}{c|}{$\mathbf{T}_{\mathbf{0}}$} \\
(sand 60-silt 40\%) & \multicolumn{2}{c|}{ (sand 70-silt 30\%) } & \multicolumn{2}{|c|}{ (sand 80-silt 20\%) } & \multicolumn{2}{|c|}{ (sand 90-silt 10\%) } \\
\hline 1 & 0,405 & 0,396 & 0,382 & 0,376 & 0,360 & 0,355 & 0,337 & 0,334 \\
2 & 0,397 & 0,386 & 0,375 & 0,367 & 0,354 & 0,349 & 0,333 & 0,330 \\
3 & 0,401 & 0,391 & 0,379 & 0,372 & 0,357 & 0,351 & 0,335 & 0,332 \\
4 & 0,405 & 0,395 & 0,383 & 0,377 & 0,362 & 0,358 & 0,341 & 0,338 \\
5 & 0,416 & 0,410 & 0,396 & 0,392 & 0,376 & 0,372 & 0,356 & 0,355 \\
6 & 0,413 & 0,405 & 0,392 & 0,386 & 0,372 & 0,367 & 0,350 & 0,349 \\
7 & 0,460 & 0,443 & 0,434 & 0,420 & 0,408 & 0,398 & 0,381 & 0,376 \\
8 & 0,461 & 0,443 & 0,433 & 0,418 & 0,406 & 0,394 & 0,378 & 0,371
\end{tabular}




\begin{tabular}{|c|c|c|c|c|c|c|c|c|}
9 & 0,433 & 0,418 & 0,409 & 0,400 & 0,387 & 0,379 & 0,364 & 0,361 \\
10 & 0,514 & 0,496 & 0,486 & 0,474 & 0,456 & 0,445 & 0,424 & 0,416 \\
11 & 0,484 & 0,465 & 0,454 & 0,440 & 0,424 & 0,414 & 0,393 & 0,386 \\
12 & 0,483 & 0,468 & 0,455 & 0,443 & 0,429 & 0,418 & 0,401 & 0,394 \\
13 & 0,418 & 0,410 & 0,398 & 0,394 & 0,379 & 0,376 & 0,358 & 0,356 \\
14 & 0,526 & 0,509 & 0,499 & 0,485 & 0,471 & 0,460 & 0,439 & 0,431 \\
15 & 0,457 & 0,440 & 0,434 & 0,420 & 0,411 & 0,402 & 0,387 & 0,381 \\
16 & 0,419 & 0,412 & 0,399 & 0,394 & 0,380 & 0,376 & 0,360 & 0,358 \\
17 & 0,609 & 0,594 & 0,578 & 0,569 & 0,545 & 0,539 & 0,506 & 0,500 \\
18 & 0,539 & 0,515 & 0,504 & 0,485 & 0,469 & 0,455 & 0,433 & 0,424 \\
19 & 0,497 & 0,479 & 0,470 & 0,458 & 0,442 & 0,431 & 0,411 & 0,406 \\
20 & 0,511 & 0,493 & 0,483 & 0,471 & 0,456 & 0,445 & 0,426 & 0,420 \\
21 & 0,685 & 0,677 & 0,649 & 0,645 & 0,609 & 0,607 & 0,569 & 0,569 \\
22 & 0,461 & 0,445 & 0,437 & 0,424 & 0,414 & 0,404 & 0,388 & 0,383 \\
23 & 0,492 & 0,471 & 0,461 & 0,445 & 0,431 & 0,418 & 0,399 & 0,394 \\
24 & 0,440 & 0,424 & 0,420 & 0,408 & 0,400 & 0,390 & 0,378 & 0,374 \\
25 & 0,567 & 0,543 & 0,531 & 0,509 & 0,495 & 0,476 & 0,460 & 0,450 \\
26 & 0,801 & 0,759 & 0,777 & 0,725 & 0,717 & 0,683 & 0,660 & 0,640 \\
27 & 0,566 & 0,545 & 0,541 & 0,523 & 0,515 & 0,501 & 0,485 & 0,477 \\
28 & 0,609 & 0,589 & 0,575 & 0,559 & 0,542 & 0,530 & 0,508 & 0,503 \\
29 & 0,586 & 0,569 & 0,557 & 0,539 & 0,542 & 0,512 & 0,496 & 0,488 \\
30 & 0,760 & 0,731 & 0,727 & 0,700 & 0,675 & 0,655 & 0,617 & 0,607 \\
\hline
\end{tabular}

675 Comparison between permuted and equivalent columns in terms of $\mathrm{T}_{0}$ for sand-silt alternations.

676 

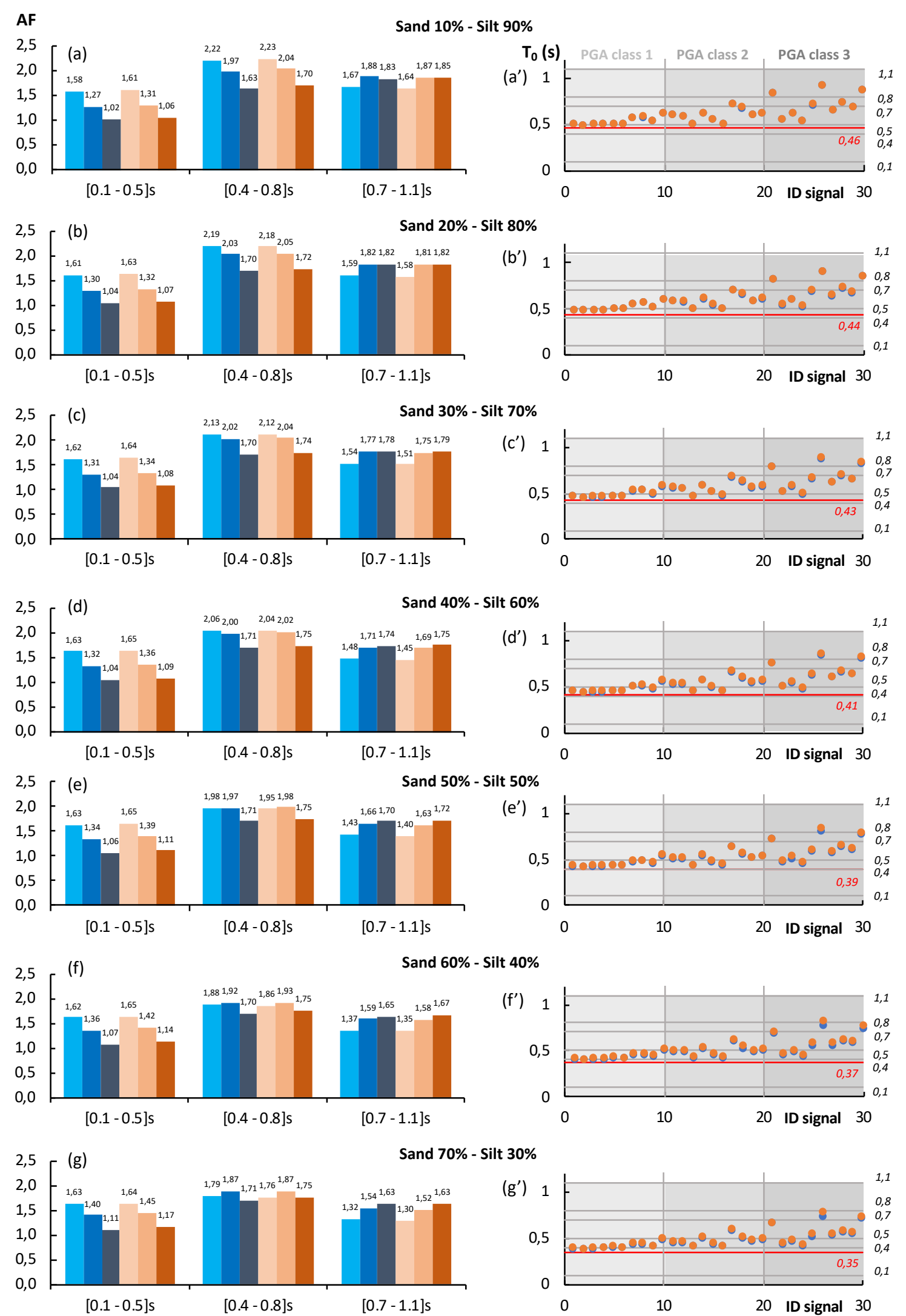

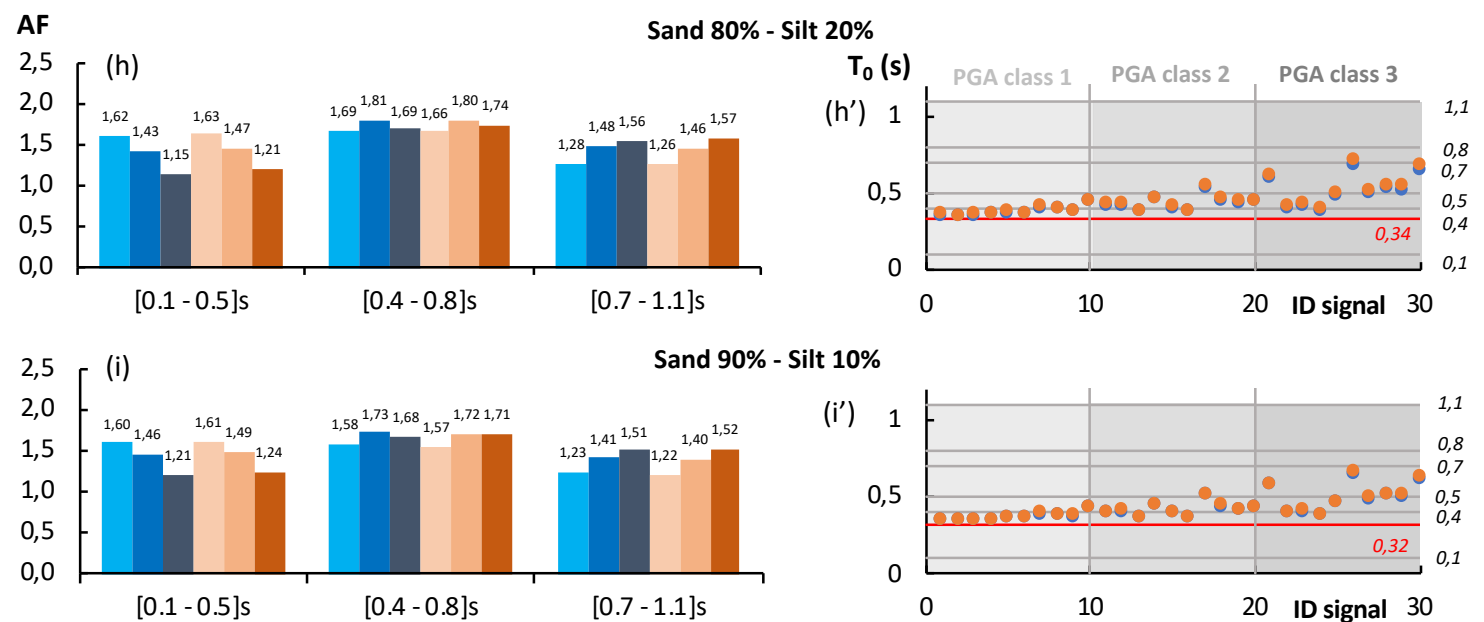
LEGEND:

- Permutations: PGA Class 1 Equivalent column: PGA Class 1

- Permutations: PGA Class 2 Equivalent column: PGA Class 2

(i')

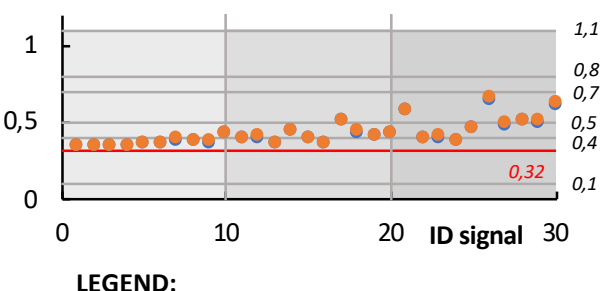

- equivalent column

- mean permutation

$-\mathrm{T}_{0, \mathrm{el}}=4 \mathrm{H} / \mathrm{Vs}_{\mathrm{eq}}$

- Permutations: PGA Class 3 Equivalent column: PGA Class 3

682

683

684

685

686

687

688

689

690

691

692

693

694

695

696

697

698

699

700

701

702

703

704

705

706

707

708

709

710

Comparison between permuted and equivalent columns in terms of (a-to-i) AF and (a'-to-i') $T_{0}$ for sand-silt alternations. 


\begin{tabular}{|c|c|c|c|c|c|c|}
\hline \multirow{2}{*}{$\begin{array}{l}\text { PGA } \\
\text { class }\end{array}$} & \multicolumn{3}{|c|}{ Permutations } & \multicolumn{3}{|c|}{ Equivalent column } \\
\hline & {$[0.1-0.5] \mathrm{s}$} & {$[0.4-0.8] \mathrm{s}$} & {$[0.7-1.1] \mathrm{s}$} & {$[0.1-0.5] \mathrm{s}$} & {$[0.4-0.8] \mathrm{s}$} & {$[0.7-1.1] \mathrm{s}$} \\
\hline \multicolumn{7}{|c|}{ AF (sand 10 - gravel 90\%) } \\
\hline 1 & 1,35 & 1,22 & 1,09 & 1,35 & 1,22 & 1,09 \\
\hline 2 & 1,34 & 1,35 & 1,18 & 1,33 & 1,35 & 1,18 \\
\hline 3 & 1,18 & 1,47 & 1,32 & 1,18 & 1,46 & 1,31 \\
\hline \multicolumn{7}{|c|}{ AF (sand 20 - gravel $80 \%$ ) } \\
\hline 1 & 1,38 & 1,25 & 1,10 & 1,37 & 1,25 & 1,10 \\
\hline 2 & 1,36 & 1,39 & 1,20 & 1,35 & 1,38 & 1,20 \\
\hline 3 & 1,20 & 1,49 & 1,33 & 1,20 & 1,48 & 1,32 \\
\hline \multicolumn{7}{|c|}{ AF (sand 30 - gravel 70\%) } \\
\hline 1 & 1,41 & 1,28 & 1,11 & 1,40 & 1,27 & 1,11 \\
\hline 2 & 1,38 & 1,42 & 1,22 & 1,38 & 1,41 & 1,21 \\
\hline 3 & 1,21 & 1,51 & 1,35 & 1,21 & 1,51 & 1,34 \\
\hline \multicolumn{7}{|c|}{ AF (sand 40 - gravel 60\%) } \\
\hline 1 & 1,44 & 1,30 & 1,12 & 1,43 & 1,30 & 1,12 \\
\hline 2 & 1,40 & 1,45 & 1,23 & 1,40 & 1,44 & 1,23 \\
\hline 3 & 1,22 & 1,53 & 1,36 & 1,22 & 1,53 & 1,35 \\
\hline \multicolumn{7}{|c|}{ AF (sand 50 - gravel 50\%) } \\
\hline 1 & 1,46 & 1,33 & 1,13 & 1,45 & 1,32 & 1,13 \\
\hline 2 & 1,42 & 1,48 & 1,25 & 1,42 & 1,47 & 1,25 \\
\hline 3 & 1,24 & 1,56 & 1,37 & 1,24 & 1,55 & 1,37 \\
\hline \multicolumn{7}{|c|}{ AF (sand 60 - gravel 40\%) } \\
\hline 1 & 1,49 & 1,36 & 1,14 & 1,48 & 1,35 & 1,14 \\
\hline 2 & 1,44 & 1,51 & 1,27 & 1,43 & 1,50 & 1,27 \\
\hline 3 & 1,25 & 1,58 & 1,39 & 1,25 & 1,57 & 1,38 \\
\hline \multicolumn{7}{|c|}{ AF (sand 70 - gravel 30\%) } \\
\hline 1 & 1,51 & 1,39 & 1,15 & 1,50 & 1,38 & 1,15 \\
\hline 2 & 1,46 & 1,54 & 1,29 & 1,45 & 1,53 & 1,28 \\
\hline 3 & 1,26 & 1,60 & 1,40 & 1,26 & 1,59 & 1,40 \\
\hline \multicolumn{7}{|c|}{ AF (sand 80 - gravel 20\%) } \\
\hline 1 & 1,53 & 1,42 & 1,17 & 1,53 & 1,41 & 1,16 \\
\hline 2 & 1,47 & 1,57 & 1,30 & 1,47 & 1,57 & 1,30 \\
\hline 3 & 1,27 & 1,62 & 1,42 & 1,27 & 1,62 & 1,41 \\
\hline \multicolumn{7}{|c|}{ AF (sand 90 - gravel 10\%) } \\
\hline 1 & 1,55 & 1,44 & 1,18 & 1,55 & 1,44 & 1,18 \\
\hline 2 & 1,49 & 1,60 & 1,32 & 1,48 & 1,60 & 1,32 \\
\hline 3 & 1,27 & 1,64 & 1,43 & 1,27 & 1,64 & 1,43 \\
\hline
\end{tabular}




\begin{tabular}{|c|c|c|c|c|c|c|c|c|c|c|}
\hline \multirow[t]{2}{*}{$\begin{array}{l}\text { ID } \\
\text { signal }\end{array}$} & Perm. & $\begin{array}{l}\text { Eq. } \\
\text { col }\end{array}$ & Perm. & $\begin{array}{l}\text { Eq. } \\
\text { col }\end{array}$ & Perm. & $\begin{array}{l}\text { Eq. } \\
\text { col }\end{array}$ & Perm. & $\begin{array}{l}\text { Eq. } \\
\text { col }\end{array}$ & Perm. & $\begin{array}{l}\text { Eq. } \\
\text { col }\end{array}$ \\
\hline & \multicolumn{2}{|c|}{$\begin{array}{c}\mathrm{T}_{0} \\
\text { (sand 10 - gravel 90\%) }\end{array}$} & \multicolumn{2}{|c|}{$\begin{array}{c}\mathrm{T}_{0} \\
\text { (sand 20- gravel 80\%) }\end{array}$} & \multicolumn{2}{|c|}{$\begin{array}{c}\mathrm{T}_{0} \\
\text { (sand 30- } \text { gravel } 70 \% \text { ) }\end{array}$} & \multicolumn{2}{|c|}{$\begin{array}{c}\mathrm{T}_{0} \\
\text { (sand 40- gravel 60\%) }\end{array}$} & \multicolumn{2}{|c|}{$\begin{array}{c}\mathrm{T}_{0} \\
\text { (sand 50 }- \text { gravel 50\% }\end{array}$} \\
\hline 1 & 0,238 & 0,237 & 0,247 & 0,245 & 0,256 & 0,254 & 0,265 & 0,262 & 0,273 & 0,270 \\
\hline 2 & 0,238 & 0,237 & 0,248 & 0,245 & 0,256 & 0,254 & 0,265 & 0,262 & 0,273 & 0,270 \\
\hline 3 & 0,239 & 0,238 & 0,248 & 0,246 & 0,257 & 0,254 & 0,265 & 0,263 & 0,274 & 0,271 \\
\hline 4 & 0,241 & 0,240 & 0,250 & 0,249 & 0,260 & 0,258 & 0,268 & 0,266 & 0,277 & 0,275 \\
\hline 5 & 0,262 & 0,263 & 0,271 & 0,271 & 0,280 & 0,281 & 0,288 & 0,288 & 0,296 & 0,297 \\
\hline 6 & 0,261 & 0,261 & 0,269 & 0,269 & 0,277 & 0,277 & 0,284 & 0,285 & 0,292 & 0,292 \\
\hline 7 & 0,285 & 0,286 & 0,294 & 0,295 & 0,302 & 0,303 & 0,309 & 0,311 & 0,317 & 0,319 \\
\hline 8 & 0,280 & 0,281 & 0,289 & 0,290 & 0,297 & 0,299 & 0,305 & 0,307 & 0,313 & 0,315 \\
\hline 9 & 0,271 & 0,271 & 0,280 & 0,281 & 0,288 & 0,289 & 0,296 & 0,297 & 0,304 & 0,306 \\
\hline 10 & 0,317 & 0,318 & 0,326 & 0,326 & 0,334 & 0,336 & 0,342 & 0,343 & 0,351 & 0,350 \\
\hline 11 & 0,295 & 0,295 & 0,303 & 0,303 & 0,310 & 0,310 & 0,318 & 0,318 & 0,325 & 0,325 \\
\hline 12 & 0,305 & 0,306 & 0,313 & 0,313 & 0,321 & 0,321 & 0,329 & 0,329 & 0,336 & 0,336 \\
\hline 13 & 0,264 & 0,264 & 0,274 & 0,273 & 0,283 & 0,284 & 0,292 & 0,293 & 0,300 & 0,301 \\
\hline 14 & 0,325 & 0,325 & 0,333 & 0,333 & 0,341 & 0,341 & 0,350 & 0,350 & 0,358 & 0,358 \\
\hline 15 & 0,297 & 0,298 & 0,305 & 0,306 & 0,313 & 0,314 & 0,320 & 0,320 & 0,328 & 0,328 \\
\hline 16 & 0,276 & 0,276 & 0,283 & 0,283 & 0,291 & 0,292 & 0,298 & 0,299 & 0,305 & 0,307 \\
\hline 17 & 0,369 & 0,369 & 0,380 & 0,379 & 0,391 & 0,390 & 0,402 & 0,402 & 0,413 & 0,410 \\
\hline 18 & 0,331 & 0,330 & 0,338 & 0,337 & 0,346 & 0,346 & 0,353 & 0,353 & 0,360 & 0,361 \\
\hline 19 & 0,308 & 0,308 & 0,316 & 0,316 & 0,325 & 0,325 & 0,333 & 0,333 & 0,340 & 0,341 \\
\hline 20 & 0,332 & 0,332 & 0,340 & 0,340 & 0,348 & 0,347 & 0,355 & 0,355 & 0,362 & 0,362 \\
\hline 21 & 0,480 & 0,479 & 0,486 & 0,482 & 0,492 & 0,493 & 0,498 & 0,496 & 0,503 & 0,500 \\
\hline 22 & 0,301 & 0,301 & 0,307 & 0,307 & 0,313 & 0,314 & 0,320 & 0,320 & 0,327 & 0,326 \\
\hline 23 & 0,297 & 0,297 & 0,305 & 0,306 & 0,313 & 0,315 & 0,321 & 0,323 & 0,329 & 0,330 \\
\hline 24 & 0,289 & 0,289 & 0,297 & 0,297 & 0,305 & 0,307 & 0,313 & 0,315 & 0,321 & 0,323 \\
\hline 25 & 0,361 & 0,361 & 0,369 & 0,367 & 0,376 & 0,376 & 0,383 & 0,383 & 0,390 & 0,390 \\
\hline 26 & 0,588 & 0,573 & 0,588 & 0,569 & 0,589 & 0,573 & 0,589 & 0,573 & 0,590 & 0,573 \\
\hline 27 & 0,399 & 0,399 & 0,405 & 0,405 & 0,411 & 0,412 & 0,417 & 0,417 & 0,423 & 0,422 \\
\hline 28 & 0,420 & 0,420 & 0,426 & 0,426 & 0,433 & 0,433 & 0,439 & 0,439 & 0,445 & 0,445 \\
\hline 29 & 0,422 & 0,427 & 0,428 & 0,427 & 0,434 & 0,436 & 0,439 & 0,436 & 0,445 & 0,445 \\
\hline 30 & 0,529 & 0,522 & 0,531 & 0,522 & 0,533 & 0,522 & 0,535 & 0,525 & 0,536 & 0,525 \\
\hline
\end{tabular}

\begin{tabular}{|c|c|c|c|c|c|c|c|c|}
\hline $\begin{array}{c}\text { ID } \\
\text { signal }\end{array}$ & Perm. & $\begin{array}{c}\text { Eq. } \\
\text { col }\end{array}$ & Perm. & $\begin{array}{c}\text { Eq. } \\
\text { col }\end{array}$ & Perm. & $\begin{array}{c}\text { Eq. } \\
\text { col }\end{array}$ & Perm. & $\begin{array}{c}\text { Eq. } \\
\text { col }\end{array}$ \\
\hline & \multicolumn{2}{|c|}{$\mathbf{T}_{\mathbf{0}}$} & \multicolumn{2}{|c|}{$\mathbf{T}_{\mathbf{0}}$} & \multicolumn{2}{|c|}{$\mathbf{T}_{\mathbf{0}}$} & \multicolumn{2}{|c|}{$\begin{array}{c}\mathbf{T}_{\mathbf{0}} \\
\text { (sand 60-gravel 40\%) }\end{array}$} \\
\hline & (sand 70-gravel 30\%) & \multicolumn{2}{c|}{ (sand 80-gravel 20\%) } & \multicolumn{2}{|c|}{ (sand 90-gravel 10\%) } \\
\hline 1 & 0,281 & 0,279 & 0,290 & 0,287 & 0,297 & 0,297 & 0,305 & 0,305 \\
2 & 0,281 & 0,278 & 0,290 & 0,286 & 0,296 & 0,295 & 0,303 & 0,302 \\
3 & 0,282 & 0,280 & 0,289 & 0,287 & 0,297 & 0,296 & 0,304 & 0,304 \\
4 & 0,286 & 0,284 & 0,294 & 0,293 & 0,302 & 0,301 & 0,310 & 0,310 \\
5 & 0,304 & 0,305 & 0,312 & 0,313 & 0,319 & 0,320 & 0,327 & 0,328 \\
6 & 0,299 & 0,299 & 0,306 & 0,306 & 0,314 & 0,314 & 0,321 & 0,321 \\
7 & 0,324 & 0,326 & 0,332 & 0,333 & 0,339 & 0,340 & 0,346 & 0,346 \\
8 & 0,320 & 0,323 & 0,328 & 0,329 & 0,335 & 0,336 & 0,341 & 0,343 \\
9 & 0,311 & 0,313 & 0,319 & 0,320 & 0,326 & 0,328 & 0,334 & 0,334
\end{tabular}




\begin{tabular}{|l|l|l|l|l|l|l|l|l|}
10 & 0,358 & 0,359 & 0,366 & 0,366 & 0,373 & 0,372 & 0,381 & 0,381 \\
11 & 0,332 & 0,333 & 0,339 & 0,339 & 0,346 & 0,347 & 0,353 & 0,353 \\
12 & 0,343 & 0,343 & 0,350 & 0,350 & 0,357 & 0,358 & 0,364 & 0,364 \\
13 & 0,308 & 0,310 & 0,316 & 0,318 & 0,323 & 0,323 & 0,330 & 0,330 \\
14 & 0,366 & 0,366 & 0,375 & 0,374 & 0,384 & 0,383 & 0,392 & 0,392 \\
15 & 0,335 & 0,334 & 0,341 & 0,340 & 0,348 & 0,347 & 0,354 & 0,353 \\
16 & 0,312 & 0,313 & 0,319 & 0,320 & 0,326 & 0,326 & 0,332 & 0,333 \\
17 & 0,423 & 0,422 & 0,432 & 0,431 & 0,441 & 0,440 & 0,451 & 0,450 \\
18 & 0,367 & 0,367 & 0,374 & 0,374 & 0,381 & 0,381 & 0,388 & 0,388 \\
19 & 0,348 & 0,349 & 0,356 & 0,355 & 0,363 & 0,362 & 0,371 & 0,371 \\
20 & 0,369 & 0,369 & 0,375 & 0,374 & 0,382 & 0,381 & 0,388 & 0,388 \\
21 & 0,508 & 0,503 & 0,513 & 0,509 & 0,518 & 0,515 & 0,522 & 0,522 \\
22 & 0,333 & 0,333 & 0,340 & 0,340 & 0,347 & 0,347 & 0,353 & 0,353 \\
23 & 0,337 & 0,339 & 0,345 & 0,344 & 0,352 & 0,353 & 0,359 & 0,359 \\
24 & 0,328 & 0,329 & 0,335 & 0,336 & 0,342 & 0,343 & 0,348 & 0,349 \\
25 & 0,397 & 0,396 & 0,404 & 0,404 & 0,410 & 0,410 & 0,416 & 0,416 \\
26 & 0,590 & 0,577 & 0,590 & 0,577 & 0,590 & 0,577 & 0,589 & 0,585 \\
27 & 0,429 & 0,429 & 0,435 & 0,434 & 0,441 & 0,440 & 0,446 & 0,446 \\
28 & 0,451 & 0,451 & 0,457 & 0,456 & 0,463 & 0,463 & 0,469 & 0,469 \\
29 & 0,450 & 0,445 & 0,455 & 0,455 & 0,459 & 0,455 & 0,463 & 0,465 \\
30 & 0,538 & 0,529 & 0,541 & 0,532 & 0,543 & 0,539 & 0,546 & 0,546 \\
\hline
\end{tabular}

Comparison between permuted and equivalent columns in terms of $\mathrm{T}_{0}$ for sand-gravel alternations. 

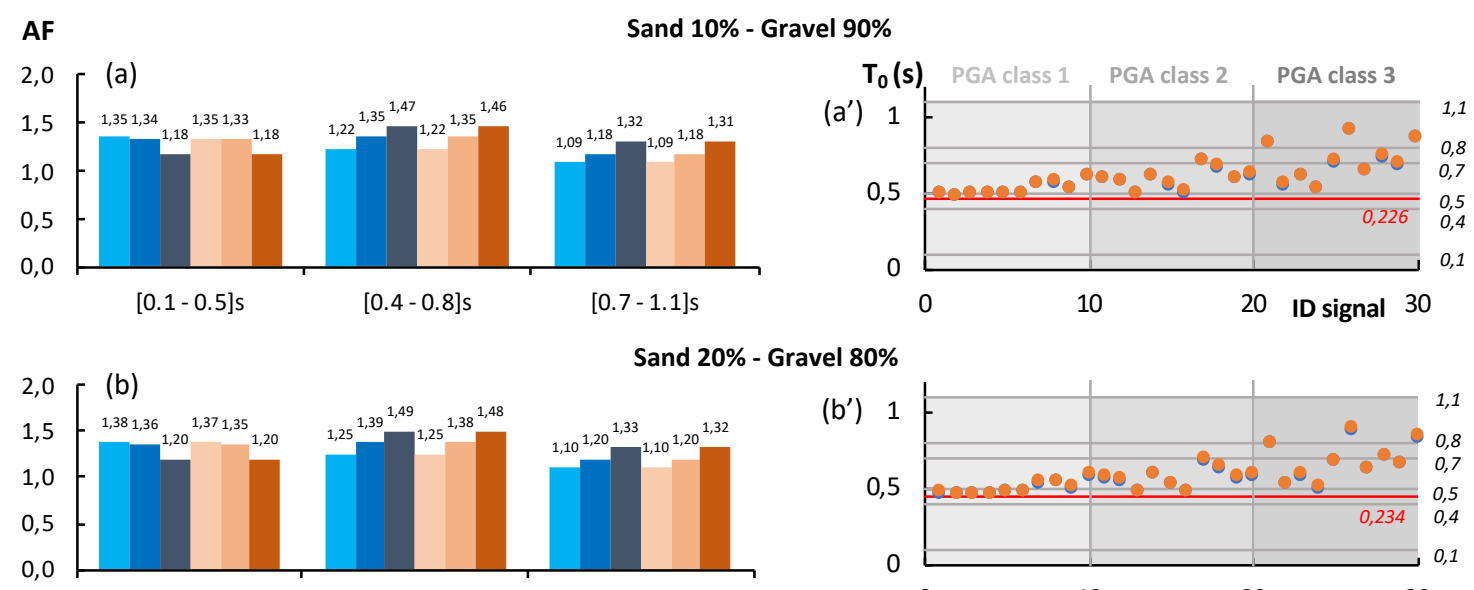

(b')

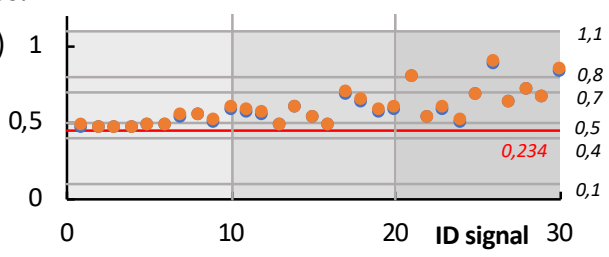

Sand 30\% - Gravel 70\%

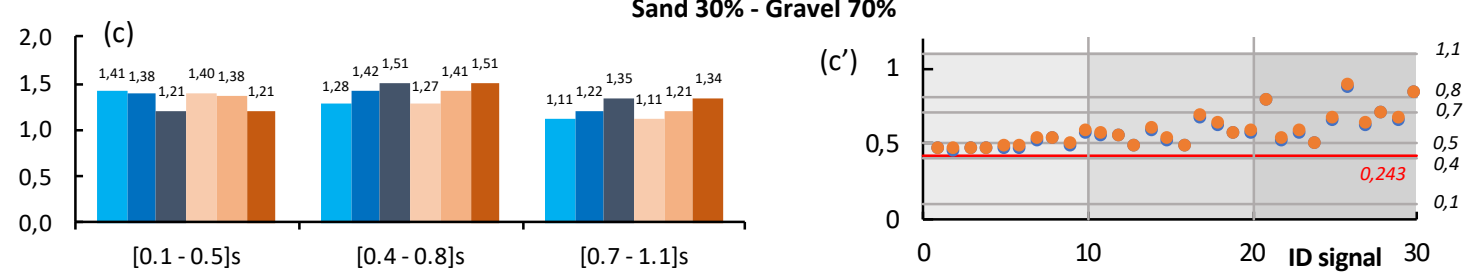

Sand $40 \%$ - Gravel $60 \%$
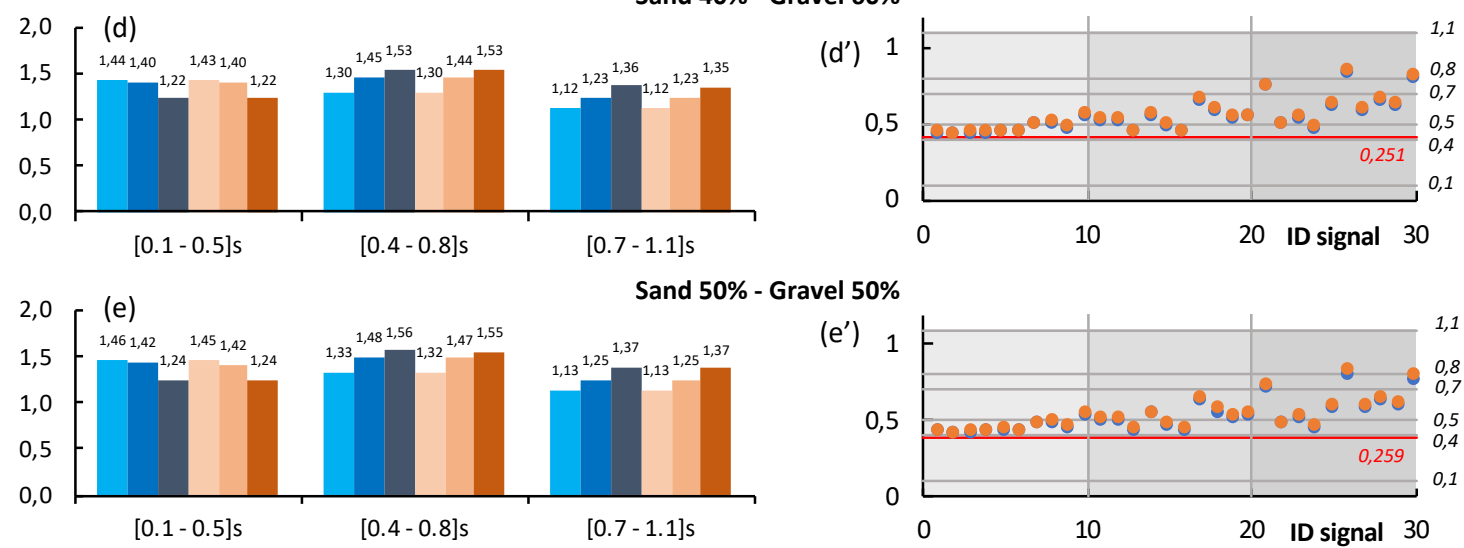

Sand $60 \%$ - Gravel $40 \%$

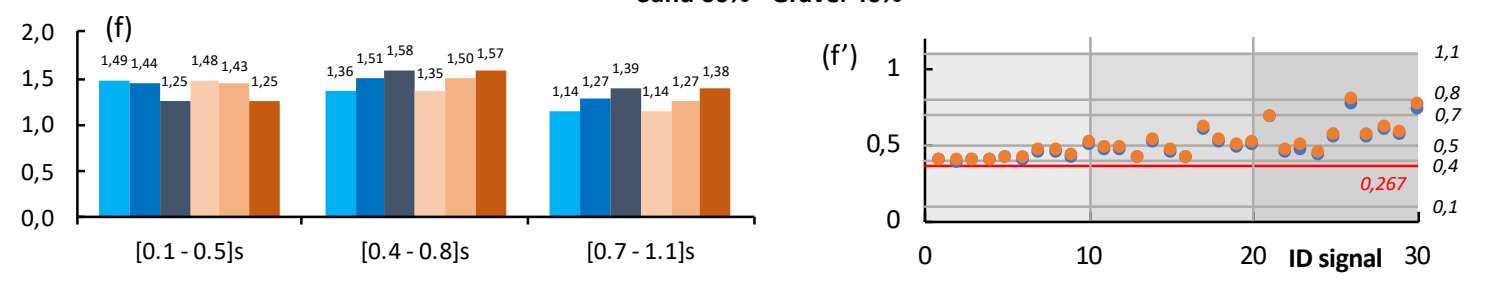

Sand 70\% - Gravel 30\%

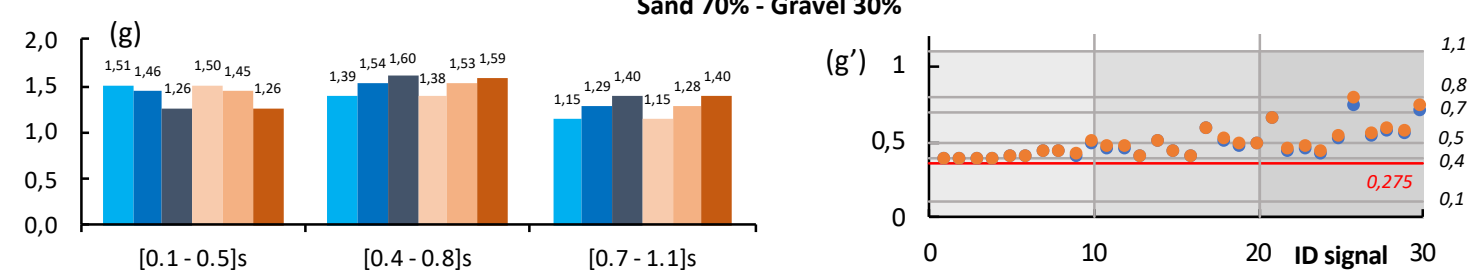




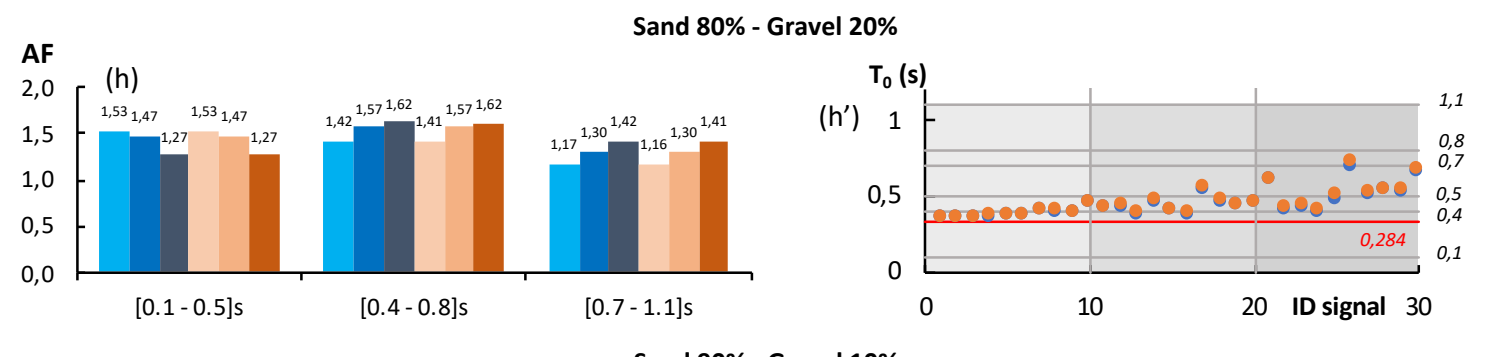

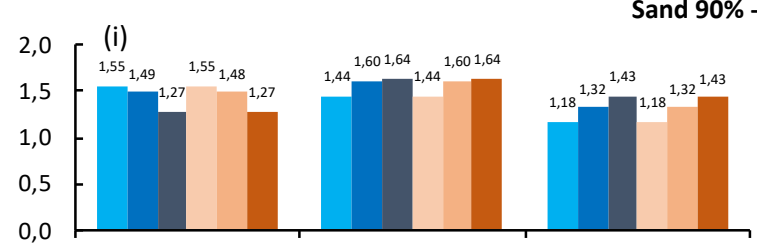

$[0.1-0.5] \mathrm{s}$

$[0.4-0.8] \mathrm{s}$

$[0.7-1.1] \mathrm{s}$ LEGEND:

- Permutations: PGA Class 1 Equivalent column: PGA Class 1

- Permutations: PGA Class 2 Equivalent column: PGA Class 2

- Permutations: PGA Class 3 Equivalent column: PGA Class 3 (i')

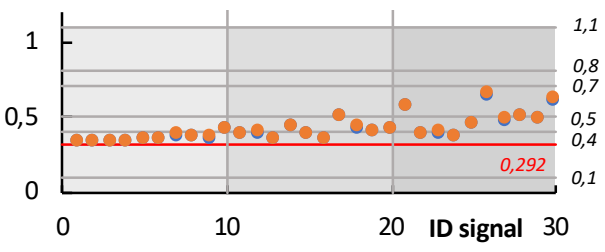

LEGEND:

- equivalent column

- mean permutation

$-\mathrm{T}_{0, \mathrm{el}}=4 \mathrm{H} / \mathrm{Vs}_{\mathrm{eq}}$
727

728

729

730
Comparison between permuted and equivalent columns in terms of (a-to-i) AF and (a'-to-i') $T_{0}$ for sand-gravel alternations. 